This article has been accepted for publication in Social Science History. This version is free to view and download for private research and study only. Not for re-distribution or re-use. (C) Cambridge University Press/The Authors. 


\title{
Business entry and exit: Career changes of proprietors in England and Wales 1851-81 using record-linkage
}

\author{
Robert J. Bennett \\ Emeritus Professor of Geography, University of Cambridge, Department of \\ Geography and Cambridge Group for the History of Population and Social Structure, \\ Downing Place, Cambridge, CB2 3EN, UK._rjb7@cam.ac.uk
}

\section{Piero Montebruno}

Research Fellow, London School of Economics, Houghton St., London WC2A 2AE P.F.Montebruno-Bondi@1se.ac.uk

\section{Carry van Lieshout}

Lecturer in Geography, The Open University, PO Box 197, Milton Keynes MK7 6BJ carry.van-lieshout@open.ac.uk

\section{Harry Smith 1LQ \\ Harry.Smith@kingston.ac.uk}

Research Fellow, Kingston University London, Kingston upon Thames, Surrey KT1

Keywords: business careers; entrepreneurs; small business; family firms; gender; railways

\section{Acknowledgments:}

This research was supported at the University of Cambridge by ESRC project grant ES/M010953: 'Drivers of Entrepreneurship and Small Businesses'. Data for 1881 was supported by Leverhulme Trust grant RG66385: 'The long-term evolution of Small and Medium-Sized Enterprises (SMEs)'. Coding the 1871 census data was supported by the ESRC and Isaac Newton Trust research grant 17.07(d): 'Business Employers in 1871'. The database used for 1851-1911 derives from an updated version of Schürer, Kevin, and Edward Higgs (2014) The Integrated Census Microdata (I-CeM). Essex: UKDS, SN-7481. We are grateful to Kevin Schürer, Alice Reid and other contributors for advice and permission to use this version. 
The figures were drawn by Phil Stickler. We are grateful for referee comments on earlier versions of the text and feedback at the EBHA conference, Rotterdam, 2019.

\begin{abstract}
The paper links the digital records of individual proprietors in the manuscript censuses 185181 for the whole of England and Wales using the BBCE database to identify career changes of employers and own account proprietors. It investigates continuing proprietorship, entry to business from previous activity, and switching out of business. The paper identifies the effects on switching of demography, gender, household relationships, sector markets, and opportunity/necessity measured by location and access to railways. Previous analysis of nineteenth-century proprietor careers has been based mainly on local case studies and large firms. This paper allows examination across the spectrum of small and large businesses for a representative sample large enough to generalise to the behaviour of the whole population. The analysis shows a larger proportion of flows between employer, own account and worker status than often expected, indicating a relatively open and flexible Victorian economy; and higher than in the modern UK. Farm and non-farm activities show contrasted patterns, with farm proprietors more stable with less switching, as to be expected. Switching appears to have slowed slightly over time, with incumbency increasing for both farm and non-farm employers, and for both men and women, but own account proprietorship was often relatively ephemeral. The paper assesses the factors influencing switching using logistic regression. This confirms age, sex, marital status, family position, location and sector as significant for explaining switching/non-switching. The results demonstrate that although open and flexible, proprietorship was highly varied between sectors, with changes of railway accessibility mainly significant for farmers.
\end{abstract}

Business entry and exit: Career changes of proprietors in England and Wales 1851-81 using record-linkage 


\section{Robert J. Bennett, Piero Montebruno, Carry van Lieshout, and Harry Smith}

\section{Introduction}

Tracking the career steps of business proprietors offers important insights for business entry and exit, and the factors influencing those career decisions. Usually historical research on proprietors' careers has been restricted by archival records to a few individuals, local case studies, or to large firms. Often it is trapped into focusing on "great men" and other forms of selection bias. The situation has changed with the release of large scale digital historical records. In Britain the manuscript nineteenth century population census is now available in ICeM (Schürer and Higgs 2014). The I-CeM-linked database of the British Business Census of Entrepreneurs (BBCE) codes those identifiable as business proprietors (Bennett et al. 2019a, 2020; resources site https://www.bbce.uk/). These data are used to give the first large-scale study tracking career changes of British business proprietors using whole-population intercensus record-linkage. This allows inclusion of proprietors of all sizes of business, from the largest to the most humble, who formed the overwhelming majority and who have often been ignored, for women as well as men, and for all social groups and industries. Having the manuscript census data also overcomes the criticisms of previous national-level census analyses that have had to use published tables (see Anderson 1999; Hatton and Bailey 2001: 105; Higgs 2005: 63-71; Higgs and Wilkinson 2016; You 2020a): that the published census under-recorded women's activities, and the extent of participation in business proprietorship was mostly never tabulated.

The analysis aims at a representative national whole-population overview by trying to link all identified proprietors in one census with adjacent census years. The linkages are then used to estimate continuities in proprietor status, and the scale and rate of switching into and out of proprietorship and how this can be explained. This allows exploration of questions about different life-stage choices for business entry and exit in different market conditions, responses 
to sector and local market opportunities, the role of family relationships, and comparison between male and female proprietorship life paths.

Proprietors are examined in two categories, employers and own account operators. Own account is the terminology used in British censuses for proprietors who employed no one else; together with employers this gives the population of self-employed business people. Although constrained by ten-year census gaps, our analysis shows that proprietorship in the Victorian era was an accessible option for many, but was highly varied between sectors, with strong contrasts by sex.

The first section of the paper introduces the theoretical background and previous literature, using interpretations from both historical and modern business studies. This provides a grounding for interpreting motives lying behind career choices. The following section describes the census data, its constraints, and how record-linkage was used. The main analysis then falls into two parts: first, to establish the scale and rate of business entry and exit; and second, to assess the main factors that explain it. The paper is focusing on linkage at scale using whole-population linkage methods. This requires searches over the whole England and Wales population each year, which range from 17.5 million people in 1851 to 26 million in 1881 . As a result it is infeasible to check all records clerically, though the results of small-scale clerical checks are quoted. The record-linked database is available as an open access download (Montebruno and Bennett 2020). The paper covers England and Wales, but can in future be extended to the Scottish BBCE digital records.

\section{Theory and previous literature}

Entry and exit to business proprietorship is a constrained choice between employment status alternatives. Our focus is between different forms of business organisation - to operate as an 
own-account sole proprietor or to employ others, and to be a proprietor as distinct from being a waged employee. Self-employment without employees could be an attractive choice allowing independence, but as recognised by the ethnographic accounts by Samuel (1975), the family studies by Davidoff (2012) and Anderson (1971), and Payne's (1988) overview, it was often associated with necessity and survival. On the other hand, taking employees into a business often marked a step to a larger and more sustained business, but could be more cumbersome and off-putting than operating alone, because of increased burdens of management and loss of independence and control (Marshall 1891: 298-300; Pollard 1965: 153; Hannah 2014: 869; Lamoreaux 1995: 43). Of course, such choices also interacted with opportunity, which was often constrained, by both supply and demand, with the result that waged employment was often preferred or the only option available. To interpret career developments we need to be able to interpret these historical choice decisions and the factors that influenced them.

\section{Historical and modern understanding of motivation}

For historical analysis we have direct evidence from contemporaneous sources of motivations for the period under investigation. Marshall and Marshall (1879: 114-34) and Marshall (1891), writing at the end of our period, directly observed the constrained choices of proprietorship through many visits to businesses. They argued that different types of proprietor operated under the same price and other signals, whether they were individual masters or employers, and hence they could be evaluated as responding to the same market challenges. Different opportunities arose in different sectors, offering differing scope for individuals depending on the level of specialisation and rarity of the skills required (Marshall and Marshall 1879: 116). Marshall (1891: 285-9) also recognised what Chandler (1962 1990) later popularised, that the field for market entry and success for the individual master and small business was narrowing, 
especially in manufacturing, where economies of scale and the application of standardisation and factory production normally gave increasing advantages to larger businesses. However, even by the 20th century Marshall took a more nuanced view than Chandler: that small firms could continue to grow in many sectors, "Though the small producer is constantly threatened with extinction ... yet he survives": ... "the number of small businesses is constantly growing" (Marshall 1919: 247-8). Indeed, he argued that smaller firms and sole proprietorship had some countervailing advantages deriving from the strong oversight available to small proprietors "the master's eye is everywhere" (Marshall 1891: 284); as well as later recognising that local external economies ("industrial districts") could particularly benefit small firms (Marshall 1919: 271; 1920: 284-5; see also Wilson and Popp 2003). Reflecting on this period, Knight (1921: 270) was one of the first to focus on this as a choice analysis: people's choices balanced uncertainty against their personal characteristics and ability, personal and local opportunities, information available, and other factors. Those individuals favouring higher security generally prefer waged employment than face the challenges of running a business. Those favouring greater independence with its risks were more willing to become entrepreneurs.

Marshall and Marshall (1879: 120-8), Marshall (1891: 614-5) and Knight (1921: 282-3) give a crucial theoretical basis as well as contemporary or near-contemporary interpretation of motivations in our historical period. They have also provided the main underpinnings of modern choice analysis so that we can interlink historical and modern interpretations (Aronson 1991; Parker 2012: 107-20). Modern understanding at a scale equivalent to historical census coverage is mainly available in the Quarterly Labour Force Survey (QLFS), the largest UKlevel fully representative survey. This shows the most frequent modern proprietorship motivations are internal (wanting better working conditions or more independence) which are nearly one third of all responses, which combined with closely connected family reasons (commitments, joining the family firm) account for 45 percent of all responses (Dawson et al., 
2014). Opportunity (23 percent), the nature of the occupation (20 percent) and necessity (12 percent) are the remainder of QLFS motivation groups. ${ }^{1}$

The same range of motives is expected to be important in historical analysis. Opportunity is particularly important for interpreting dynamics: the career steps to improve income through exploiting market openings, as well as the obverse of necessity (such as redundancy and unemployment) where self-employment is forced because of lack of other options as a survival strategy to meet family income needs (Samuel 1975; Anderson 1971; Davidoff 2012). The nature of the occupation is also critical as sectors are a primary factor in career choices. Many fields historically, as now, could be pursued only, or mainly, through self-employment (Marshall 1891: 288-90; Clapham 1932; Checkland 1964; Payne 1988): the vocations and professions (musicians, artists, lawyers, doctors, agents); many construction trades (such as joiners, plumbers, plasterers and bricklayers) were operated then, as now, by own-account individuals; much of retail and hospitality industries also had numerous own account traders (especially for women and widows running shops and inns: Davidoff 1995; Garrett et al. 2001; Kay 2009); and many brokers and agents were also predominantly sole proprietors or partnerships.

In practice motivations overlapped. All individuals historically were influenced by personal, family and social conditions, which overlapped opportunity and necessity especially deriving from family commitments, and particularly for women (Anderson 1991; Nenadic 1991; Davidoff and Hall 1997). By using family resources a firm could potentially reduce start-up and continuing running costs: using family labour, family capital and networks (Marshall 1891: 298-300; Penrose 1959; Anderson 1991; Colli 2003). Connections beyond the immediate family could also draw resources from distant relations, from boarders, and from wider social networks (Davidoff and Hall 1997; Owens 2002). Prior experience could also be significant

\footnotetext{
${ }^{1}$ Frequencies rescaled to aggregate groups from Dawson et al. (2014: Table 3).
} 
within, as well as outside a family firm, and should be shown in historical linkages. Experience could facilitate entry into any status and might follow a "ladder", as suggested in some historical studies (Nenadic 1991; Nenadic et al. 1992; Davidoff 2012), with "entry-level" sectors and types of entrepreneurship following stepping stones from being waged, to own account, to taking on employees (Church 1993; Davidoff 2012) which could be facilitated by following parents (Marshall 1891: 298-300; Long 2013). Such entry effects are also indicated in modern studies (e.g. Aronson 1991; Parker 2012; van Der Zwan et al. 2011). However, historically Miles (1991), Mitch (1993) and Morris (2005) indicate that there were many constraints for entry into some walks of life, and this is confirmed by Marshall and Marshall's (1879: 116-7) observations of market barriers to some sectors and occupations.

\section{Career choice from inter-census record-linkage}

For the historical record-linked census data here, we are interested in establishing how far switching actually occurred and assessing how it can be explained. Historical data are of course constrained, and information on one of the key incentive variables, wage rates, is not available for this period at sufficient scale or locational and sectoral detail. However, as shown in Crossick's (1978: 49-57) case study of 1851 Kentish London, wage differentials may not be crucial. Most own-account proprietors earned almost the same as workers, and skilled and semi-skilled artisans.

In our analysis we can include most key internal motives. Previous historical research suggests a key role of sex, family and other relationships in entry and exit from proprietorship that should be revealed in record-linked data. As already noted, the role of the family is wellestablished by Anderson (1971, 1988), and Davidoff and Hall (1997), among many others, who demonstrate family, fertility, kinship, inter-generational ties and co-residence as key features of personal development in the nineteenth century, though making reference to business roles 
primarily through classifications of social class. Large-scale census analyses also confirm the critical role of the family, but they generally do not separate proprietors from classes nor engage with entry and exit issues: e.g. Davidoff (2012: Appendices) using breakouts from the 1881 census, Anderson (1988) using the 5 percent sample of the 1851 census, Long (2013) using the 1881, 1901 whole population and 2 percent 1851 census sample, and Garrett et al. (2001), Schürer et al. (2018) and You (2020) using 1881 whole population coverage. Family and wider networks for larger employers could allow maintenance of control of the firm through flexible methods of profit sharing, flexible forms of entry and exit by family members, and expansion of capital using close kin and wider networks of trust relationships that facilitated succession planning (Pollard 1965; Payne 1988; Church 1993; Rose 1994). At least three quarters of firms were family owned or controlled up to 1911 (Colli 2003). Marshall (1919: 314) called them "the representative firm in most industries", whilst Clapham (1932: 112) noted that masters and small firms were "the most numerous form of enterprise". Two more detailed case studies are indicative of entry and exit patterns: for Kentish London in 1851 (Crossick 1978) and for northern England and Edinburgh (Nenadic et al. 1992; Nenadic 1993). These link census and other records and demonstrate entry to both employer and own account status through family. However, higher income households had greater ability to recruit non-conjugal ties into trades such as drapers, wine merchants, licensed victuallers, chemists and druggists. But in poorer trades (such as fishmongers, greengrocers and general dealers) nuclear family groups of interdependents were common and could be a source of self-exploitation (Crossick 1978; Crossick and Haupt 1995: 102).

Gender interacted with demography and social measures mainly through women having reduced opportunities for entry into proprietorship because of lifecycle constraints from motherhood, family responsibilities and access to finance. Women also experienced barriers to accessing many waged employment opportunities. This could mean that proprietorship was sometimes a more available alternative. However, entry was often restricted for proprietorship 
as well. Previous historical research suggests gender-specific differences in the frequencies and sectors of male and female proprietorship (Nenadic 1993; Kay 2009; Davidoff 2012; Aston 2016; Aston and Bishop 2020), with large employers almost completely male (Nenadic 1991), though with a stronger participation from widows who inherited a spouse's business (Wall 2002; Kay 2009; Davidoff 2012). Recent large-scale census analysis confirms that high rates of female proprietorship were limited to a narrow range of sectors. It also shows critical differences between women: proprietorship was a route to independence that was otherwise difficult for many single women; but for married women it was important for offering opportunities to supplement family income, especially where necessity required it (Smith et al. 2020; Bennett et al. 2019b: 169-74).

The census is locationally specific in $\mathrm{I}-\mathrm{CeM}$ at the small scale of parishes. This allows assessment of opportunity-necessity dimensions of motivations in terms of location. There were two key locational changes of this period. The first was the continued expansion of urban areas (Law 1967; Robson 1973). This brought more of the population into closer proximity, living and working at higher densities that facilitated local market expansion, and hence new opportunities for small business entry. The second source of locational change was the latestage developments of the rail network. By 1851, at the start of the analysis, most main settlements in England and Wales were already well-connected to rail (Mitchell 1964; Simmons 1986). Hence, aggregate effects of changing accessibility will be relatively small, but changes at a local level were still potentially significant. Rail for this period continued to be the most important vector of change in transport infrastructure and its main effect 1851-81 was expansion of branch lines to facilitate greater penetration of the national market by larger businesses, either through expansion of wholesaling and distribution, or giving opportunities for local branches of retail outlets (Marshall 1891: 348; Jeffreys 1954; Novak and Gilliland 2011). The effects of large firm expansions and branch networks were relatively limited at the 1851 start of the period of analysis, but were accelerating by 1871-81 with increasing 
competitive pressures the small master (as noted in the quotation from Marshall above) in craft manufactures, maker-dealing and retailing.

Census record-linkage also gives potential for both aggregate and fine-grained analysis by business sector. Because the purpose of the paper is a representative national overview, we focus analysis on 13 aggregate sectors, and the main contrasts of farm and non-farm sectors. Sectors are a key means to interpret entry and exit. Marshall and Marshall (1879: 116-7) suggest that proprietors should be more easily able to switch occupational sectors than workers: "the business man has great opportunities for discovering whatever can be found out about the present and future of other trades; if he wishes to change his trade, he can ... generally do so more easily than a skilled workman ... if there were no natural or artificial barriers against entering a trade". Sectors were also a major differentiator of competitiveness and opportunity since they determined the scope and costs of entry barriers, scope for economies of scale, and influenced the value of incumbency and costs of exiting (Marshall and Marshall 1879: 116). Marshall (1891: 288-90), Clapham (1932), Checkland (1964), and Lee (1971) indicate the sectors that were most critical to the historical dynamics of the economy and how opportunities opened (or closed) over time. We expect there to be major contrasts at aggregate sector level between, on the one hand, sectors such as refreshments, maker-dealing, many individual building trades, and some personal services which had very low entry costs and barriers, and on the other hand the major manufacturing sectors, chemicals, utilities, construction management such as "builders", and the professions that had high entry barriers and/or capital needs. High exit costs and low elasticity produce contrasts between sectors with low exit rates where there are high sunk capital and high skills, compared to sectors with low entry costs. Sector inertia and immobility between status categories of proprietors and worker will also be influenced by sector locational dominance. Although Britain was becoming an integrated market, de facto local monopolies could still exist that limited entry (Marshall 1891: 286). As 
Crafts and Mulatu (2005) and Lee $(1971,1981)$ highlight, full market integration in Britain was not general until the 1940s.

\section{The census data and record linkage}

The census offers the enormous advantage of full population coverage, thus overcoming selection bias and allowing a view of the development of business development across the whole economy and all sectors. It has, however, various limitations of design and collection in the way that proprietors can be identified. These have to be managed to ensure that the advantage of full population coverage is supported by linked records that are representative of the population.

\section{Census questions on proprietors}

The British censuses for 1851-81 included a question that was unique to this period. This requested information on "employers" and "masters" (which censuses also referred to as own account). The key part of the question in 1851 was: "In TRADES the Master is to be distinguished from the Journeyman and Apprentice, thus - '(Carpenter - Master employing [6] men);' inserting always the number of persons of the trade in his employ on March 31 st". $^{2}$ This was extended in 1861 to: "In TRADES, MANUFACTURES, or other Business, the Employer must, in all cases, be distinguished. - Example: 'Carpenter - Master, employing 6 men and 2 boys;' inserting always the number of persons of the trade in their employ, if any". 3 For farmers there were similar questions. The instructions continued almost identically for

\footnotetext{
2 'General Instruction', Census of England and Wales, Householder's Schedule, 1851; all brackets and italics in original.

3 “'General Instruction', Census of England and Wales, Householder's Schedule, 1861.
} 
1871 and $1881 .{ }^{4}$ Though not the best question design, the census manuscripts give the original responses by employers to state their business and its workforce size, with similar descriptors for masters.

The digital census records in I-CeM (Schürer and Higgs 2014) give the respondent descriptor strings, but proprietors are not identified directly. They have been extracted in the I-CeMlinked database of BBCE (Bennett et al., 2020) which tags all employers in the census records with their workforce, and those operating on own account with no employees (Bennett et al. 2021). The tagging assigns each response to employer, own account status using all synonyms of "employer" and "master", such as "proprietor", "partner", "owner", "landlord/landlady" of an inn, etc., and tagging anyone who stated having employees (or "workers", "hands", etc.). The identification of these categories used algorithms with subsequent clerical checks and hand cleaning (Bennett and Newton 2015). The directly tagged responses can be confidently treated as either, respectively, employers or own account; they provide the entry point for our record linkage.

\section{Linking inter-census records}

Record-linkage methods have been widely applied to censuses (Winkler 2014; Zhichun et al. 2014). Usually census linkage has focused on social changes (e.g. Long, 2013; Long and Ferrie 2013). However, Atack et al. (1992) piloted linkage of a sample of proprietors between the 1860 and 1880 US Census of Manufactures, and Nenadic et al. (1992) developed proprietor linkage for case studies. But this paper is one of the first to attempt linkage of proprietor records over four census years for a whole population. The linkages cover ten-year inter-census gaps. Hence, linkage criteria have to be persistent and complete. Persistence restricts linkage to five

\footnotetext{
${ }^{4}$ Images of the question instructions are available in Higgs et al. (2015) and enumerator instructions are summarised by Higgs (2005). https://www.essex.ac.uk/research-projects/integrated-census-microdata\#the-icem-guide
} 
criteria: surname, forename, birthplace, exact age (by year), and sex. Completeness of all responses is often ignored in census studies: the level of non-response to the occupation question prevents this being used as a link criterion. Linkage criteria also have to be independent of the subsequent analysis: so that occupation and proprietor status cannot be used. The method follows Jaro-Winkler who pioneered large-scale census linkage (Porter and Winkler 1997). ${ }^{5}$ It uses string comparison of first and second names, modified here by data blocking, and variable thresholds for acceptance of matches based on name frequency. There was also extensive pre-cleaning, and prior standardisation and coding of proprietor status and birthplace descriptors. ${ }^{6}$ Full details of method are given in Newton and Bennett (2020) and database in Montebruno and Bennett (2020).

For each year the starting point was the proprietors directly tagged from the census manuscripts, which range in number from 385,530 in 1851 to 414,939 in 1881 . Each of these was searched for matching individuals in adjacent years against the whole population available, irrespective of their occupation and proprietor status. Both forward and backward record linkage was used. The average linkage achieved was 22.7 percent of the starting population of tagged employers and masters. ${ }^{7}$ This linkage rate is fairly typical for census linkage lacking accurate training data, and where transcription errors and variations in name recording occur (Winkler 2014; Massey 2017; Goeken et al. 2017; Antonie 2020); it is almost identical to that achieved by Long (2013: Table 1). ${ }^{8}$ It also reflects drawing match thresholds high to minimise false positives to maximise accuracy. Most important, however, the match rates were representative of the original tagged entrepreneur population for the combined forwards- and backwards-linked data. Combining linkages overcomes the most common problems of bias

\footnotetext{
${ }^{5}$ The Jaro-Winkler algorithm was sourced from FEBRL (Freely Extensible Biomedical Record Linkage): Christen et al. (2005).

${ }^{6}$ Coding and cleaning of proprietors summarised in (van Lieshout et al. 2017); birthplace standardisation follows Schürer et al. (2015), Schürer and (2019).

${ }^{7}$ See (Montebruno and Bennett 2020: Table 1)

${ }^{8}$ Long does not distinguish employment status: farmers are his only social group that is predominantly proprietors
} 
that arise in linkage studies: forward unrepresentativeness by age as a result of differences in survivorship by sex, class or other characteristics; and backwards unrepresentativeness by excluding young people who were at early stages of careers.

Employers and own account are relatively rare (only 2-5 percent of the population). For rare items the main danger in linkage is false positives, which increase very rapidly with any weakening of the linkage criteria. Hence, we focused on minimising false positives. Because no training data or alternative fully accurate "truth" data are available that can be used at the scale of the whole population it is essential to have strong confidence in the accuracy of the links. This meant rejecting those with multiple links and there is no alternative means of “disambiguation", e.g. as used by Antonie et al. (2020). As a result of this and high thresholds we will have lost people who were truly linked: we have high accuracy, but low "efficiency" (Abramitzky et al. 2020). Our key tests for linkage were: is the $\mathrm{N}$ large enough for robust analysis without this risk; and is the sample representative? As we achieved an $\mathrm{N}$ of many thousands, and it proved to be representative, it is unnecessary to increase $\mathrm{N}$ for the purpose of analysis by weakening the linkage criteria (we are not generally constrained by sample size in this paper). Hence, our key test of accuracy is statistical representativeness of the samples against the original census.

Tests of the combined linked samples compared with the original groups of the tagged population found no significant differences at $\mathrm{p}=0.05$ between them in aggregate, and for categories of farm and non-farm, by status, age, sex, and size-class of the workforce reported; i.e. the linked sample is representative of the tagged starting population from which links were made (Montebruno and Bennett 2020). These tests also indicate that archival losses do not affect representativeness; although reducing the number of links that can be found, the tests show data loss has random effect on linkage. ${ }^{9}$ However, for non-farm females linking 1871 -

\footnotetext{
${ }^{9}$ For England and Wales a proportion of the records is missing: 2.0 percent for 1851, 3.7 percent for 1861, and 0.1 percent for 1881 (van Lieshout et al. 2020).
} 
61 , there was significant difference at $\mathrm{p}=0.01$ which had different match rates by status: higher for employer matches than own account. This arises from constraints of the 1871 data discussed below.

A further test is linkage accuracy. Although we have no fully "truthed" data we can make manual checks against the census manuscripts. We checked 600 linked records identified as potentially aberrant (young age, strange transcripts, etc.); given that linkage was deployed for 17.5-26 million people per year, full clerical checks of the records are infeasible. Checking spouse name, family configuration and other characteristics indicated no links looked erroneous. However, 3 ( 0.5 percent) had errors in employer status because part or all the original data on the employer was mis-transcribed and attributed to the person immediately below the true subject: i.e. the correct person was linked, but given the wrong status. This issue of "split-lines" was identified at an early stage of constructing the entrepreneurs' database. It had been the subject of extensive previous hand cleaning, but a few slipped through (van Lieshout et al. 2017).

The very low error rate contrasts with most census linkage studies, which typically find around 20 percent false positives (Zhichun et al. 2014; Massey 2017; Goeken et al. 2017; Abramitzky et al. 2020); e.g. Bailey et al. (2020) found two independently digitized versions of the 1940 US Census had 25 percent of records with different transcriptions of last name. The method applied here links what can be linked confidently; other researchers will be able to find more links within the same data but may not achieve the same level of accuracy. Our aim is a representative starting point that is sufficient to support our analysis. The nature of the entrepreneur also seems to offer better matching opportunities: employers in particular tend to be more stable than the rest of the population as they are more rooted by their investments, and they tend to be older (Bennett et al. 2019b: 164-70) and we already know that a large proportion of migration occurred primarily in young adult years (Schürer and Day 2019). We might expect 
farmers to be easier to link as they were often more occupationally stable with less mobility out of proprietor status (as found for intergenerational links by Long and Ferrie 2013: Appendix Tables A3-3, A3-4), which proves to be the case below; but actually linkage rates hardly differ between farm and non-farm. Similarly, female proprietresses were expected to be more difficult to link, as found in most previous census studies of women (Massey 2017; Zhichun et al. 2014) because of name changes on marriage/re-marriage. But female employer link rates are actually higher than male (primarily because they were already married in the initial link years), whilst own-account proprietresses usually have only slightly lower link rates.

There are, however, two constraints on the analysis. First, the imperfect design of the question and its interaction with other census instructions led to incomplete or non-responses because some respondents were diverted from giving a full reply. Hence, tagged proprietors may link to imperfect responses with uncertain employment status in other years. To overcome this deficiency the BBCE database provides supplements of imperfect responses by assigning all economically active to employer, own account, or worker status. This means that individuals tracked between years have either a tagged or an estimated proprietor status. This is approximate. ${ }^{10}$ The result of including or excluding the supplemented responses was tested in the following analysis to check robustness; the analyses did not differ substantively so that only the supplemented results are shown. However, this increases the variance encountered, as borne in mind below.

A more major data constraint is that I-CeM data for 1871 do not currently exist. The BBCE database infills this gap from an alternative transcription source. ${ }^{11}$ However, this infill covers only the tagged groups of employers and masters. This means that searches for linked

\footnotetext{
${ }^{10}$ See (Bennett et al. 2021). The method adjusted non-responses using individual occupation string descriptors, sex, relationships within households, demographic filters, and statistical relationships for full employment status responses in 1891 and 1901, where the census design produced more complete responses.

${ }^{11}$ Because the genealogy provider to I-CeM (FindMyPast) does not have marital status, birthplace and occupation transcriptions for 1871, I-CeM excluded it as many derived codes cannot be constructed. The database used in this paper infills 1871 from another transcription source (S\&N: The Genealogist: see van Lieshout et al. 2018).
} 
proprietors into 1871 from adjacent years cannot search the whole population. As a result, forward links 1861-71, and backwards links 1881-71 have a lower probability of success. This limits interpretations for 1871. Consequently we place most emphasis below on the strongest data for 1851-61 linkage, and use 1871 mainly as an indicator of general trends.

\section{Analysis}

The census offers the enormous advantages of full population coverage. However, we are only able to observe proprietors at 10-year intervals, which means that there may have been other intermediate activity differing from the states we can observe at the start and end of a linkage. This means that "entry" refers to the observed state prior to the subsequent census date, and "exit" is the state reached at the later date.

Table 1 summarises the full record-linked sample, combining forwards and backwards links, and differentiating farming from non-farming. ${ }^{12}$ This is an example of linkage comparison for 1851-61, showing the transition from one status (row) in 1851, to another status (column) in 1861. The 1851-61 linkage is the fullest from the data available as it avoids the limitations of the 1871 data. As combined links the matrix covers all identified linked people, irrespective of whether identified forwards or backwards. This means that the rows show the full extent of exit from proprietorship, and the columns show the extent of market entry. The diagonal entries are those who do not change status: the largest of these (top left) shows 20,290 employers in 1851 who continued to be employers in 1861 . These tables are proprietor switches; they are not full matrices of status switching for the whole population because we are tracking only entry/exit of proprietors. Switching between worker and "other" categories is incomplete because these two statuses only occur in the table for those people who had been proprietors at

\footnotetext{
${ }^{12}$ Aggregate definition of agriculture; The table combines tagged and supplemented data
} 
one end of the link. In the population at large worker-to-worker changes will be the majority. The worker-to-worker links in Table 1 refer only to those who became proprietors in the later linked years. This bottom right quadrant is excluded in Tables 2 and 3, as indicated by the shading.

\begin{tabular}{|c|l|r|r|r|r|r|}
\hline \multicolumn{2}{|c|}{ Non-farm } & \multicolumn{6}{|c|}{ Later status 1861: entry } \\
\cline { 3 - 8 } & Employer & \multicolumn{1}{l|}{$\begin{array}{l}\text { Own } \\
\text { account }\end{array}$} & Worker & Other & \multicolumn{1}{l|}{ Total } \\
\hline \multirow{3}{*}{$\begin{array}{c}\text { Prior } \\
\text { status }\end{array}$} & Employer & 20290 & 6985 & 14971 & 1873 & 44119 \\
\cline { 2 - 8 } $\begin{array}{c}\mathbf{1 8 5 1}: \\
\text { exit }\end{array}$ & Own & & & & & \\
\cline { 2 - 8 } & Worker & 19313 & 7332 & 10727 & 1562 & 27934 \\
\cline { 2 - 8 } & Other & 6141 & 12525 & 5423 & 216 & 37370 \\
\cline { 2 - 8 } & Total & 53950 & 29356 & 33404 & 3651 & 120361 \\
\hline
\end{tabular}

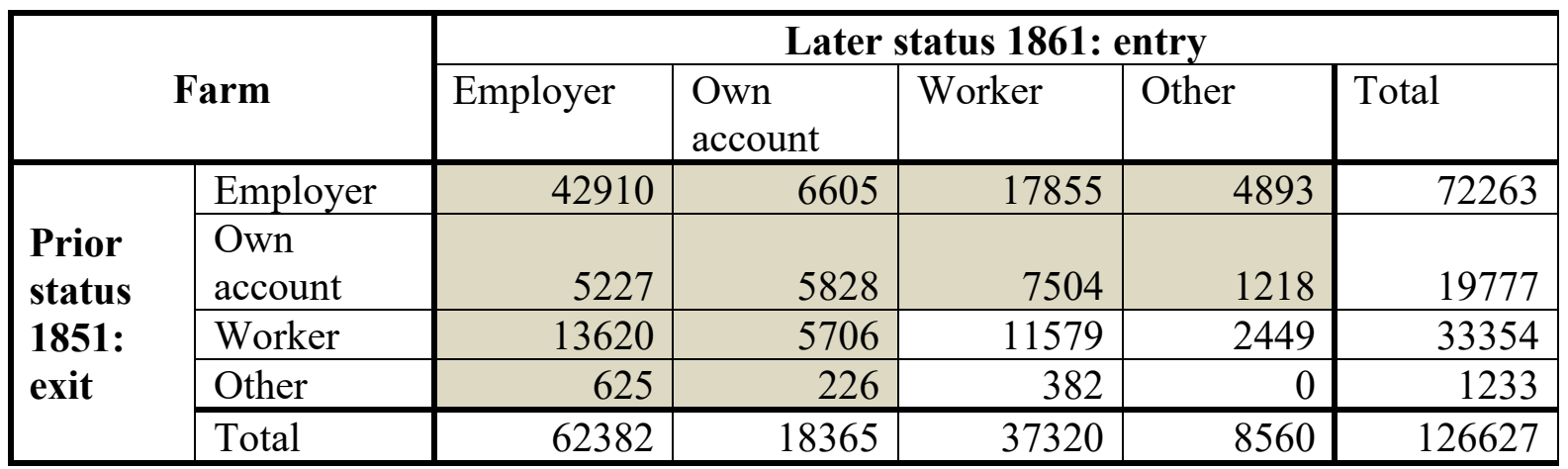

Table 1. Numbers of proprietor switching status: exiting from an 1851 employment status (rows) and entering an 1861 status (columns); shaded area is the main focus of subsequent analysis since the unshaded area is not a full sample of switching for workers and others.

"Other" in this table refers to an occupational status where linked proprietors were economically inactive, i.e. not employers, own account, or workers. It reflects various important features of the dynamics of proprietor development. The largest group, as expected, is for over three quarters who were too young to be previously occupied or were scholars or 
"farmer's son" etc. Another group was the retired, unoccupied and living on independent means reflecting exiting business in later years. A small group is "private means" and landowners, who were recorded as proprietors at one end of the link. They reflect those on large private incomes or having large estates, perhaps as an element of "gentlemanly capitalism".

\section{Change of entry/exit rates over time}

Similar matrices for each year allow comparison of status change over time. However, to ensure comparability between links that have different sample sizes, as well as to limit the effect of the partial data for 1871, it is preferable to present results as percentages. Percentages for linkage can be calculated in two different ways: first, as the different exit statuses from a specific prior status (e.g. in Table 1 the rows sum to 100 percent); and second, percentages of the sources of entry from all prior statuses (the columns in Table 1 sum to 100 percent). These are referred to in the rest of the paper as entry and exit percentages; they are shown, respectively, in Tables 2 and 3 for the 1851-61 changes, which correspond with the shading in Table 1.

Entry statuses are shown in Table 2. While many farm employers are stable (69 percent continue as farmers), non-farm employers in 1861 originate almost as frequently from worker status as being previously employers in 1851 . For own account the pattern is similar, with farmers more stable than non-farmers, and workers a major prior entry source for each. In contrast, own-account non-farm have a higher entry proportion (43 percent) from workers than farm (32 percent). As previously recognised by Crossick's (1978: 49-57) case study, the flows between worker and proprietor status are high. There may be some effects of 10 -year intervals between censuses which may hide switches of status that conform to a 'ladder' that we cannot observe, but it appears that moves between employer and worker status are frequent without going through an intermediate status of own account. 


\begin{tabular}{|c|l|r|r|}
\hline \multicolumn{2}{|c|}{ Non-farm } & \multicolumn{2}{c|}{ Later status 1861: entry } \\
\cline { 3 - 4 } & Employer & Own account \\
\hline \multirow{4}{*}{$\begin{array}{c}\text { Prior } \\
\text { status }\end{array}$} & Employer & 37.6 & 23.8 \\
\cline { 2 - 4 } & Own & & \\
exit & account & 15.4 & 25.0 \\
\cline { 2 - 4 } & Worker & 35.6 & 42.7 \\
\cline { 2 - 4 } & Other & 11.4 & 8.6 \\
\cline { 2 - 4 } & & 100 & 100 \\
\hline
\end{tabular}

\begin{tabular}{|c|l|r|r|}
\hline \multicolumn{2}{|c|}{\multirow{2}{*}{ Farm }} & \multicolumn{2}{c|}{ Later status 1861: entry } \\
\cline { 3 - 4 } & Employer & Own account \\
\hline \multirow{4}{*}{\begin{tabular}{c} 
Prior \\
status \\
\cline { 2 - 4 } \\
\cline { 2 - 4 } \\
1851: \\
exit
\end{tabular}} & Own & 68.8 & 36.0 \\
\cline { 2 - 4 } & account & & \\
\cline { 2 - 4 } & Other & 8.4 & 31.7 \\
\cline { 2 - 4 } & Total & 1.8 & 31.1 \\
\hline
\end{tabular}

Table 2. Entry percentage from each status in 1851 to become employer and own account proprietors in 1861 (each column sums to 100 percent).

Exit status in Table 3 was also relatively stable for employers: 46 percent of all non-farm employers and 59 percent of farm employers remained as employers over the 10 years 1851 61 , with the main subsequent exit status being to worker, followed by own account. This is a strong contrast with own-account proprietors, where only 26 percent were stable in this status in non-farm and 29.5 percent in farming, with the main exit status in each case being 38 percent to become workers.

Whilst the high level of stability in the same status on entry and exit is to be expected incumbency offered many advantages and few incentives to change, and as Marshall (1891: 285) noted agriculture and many small traders had few opportunities to upscale - the relatively large proportion of both employers and own account who moved out of or into workers demonstrates that a "ladder" on entry and business succession from employer status into own account was not necessary or most common. It also runs counter to more general comments on 
the lack of social mobility, upwards or downwards, observed in Victorian marriage pattern by Miles (1999: 177) or the father-son mobility examined by Mitch (1993), but fits with the findings of others who have focused more specifically on proprietors, such as Crossick (1978) for 1851 London, that there was frequent flow between own-account and employee status. In this period our results show the flows between worker, employer and own-account statuses are all large, and that own-account was one of the least stable of categories over time. This confirms other literature that suggests that own account was a relatively fragile and more ephemeral way of earning a living, often associated with necessity entrepreneurship when wage options were not available, and that small traders and employers were increasingly under challenge (Marshall 1891: 283-4).

\begin{tabular}{|c|c|c|c|c|c|c|}
\hline \multirow{2}{*}{\multicolumn{2}{|c|}{ Non-farm }} & \multicolumn{5}{|c|}{ Later status 1861: entry } \\
\hline & & \multirow{2}{*}{$\begin{array}{r}\text { Employer } \\
46.0 \\
\end{array}$} & \multirow{2}{*}{$\begin{array}{l}\begin{array}{l}\text { Own } \\
\text { account }\end{array} \\
15.8\end{array}$} & \multirow{2}{*}{$\begin{array}{r}\text { Worker } \\
33.9\end{array}$} & \multirow{2}{*}{$\begin{array}{r}\text { Other } \\
4.2\end{array}$} & \multirow{2}{*}{$\begin{array}{ll}\text { Total } & \\
& 100\end{array}$} \\
\hline Prior & Employer & & & & & \\
\hline $\begin{array}{c}\text { status } \\
\text { 1851: } \\
\text { exit }\end{array}$ & $\begin{array}{l}\text { Own } \\
\text { account }\end{array}$ & 29.8 & 26.2 & 38.4 & 5.6 & 100 \\
\hline
\end{tabular}

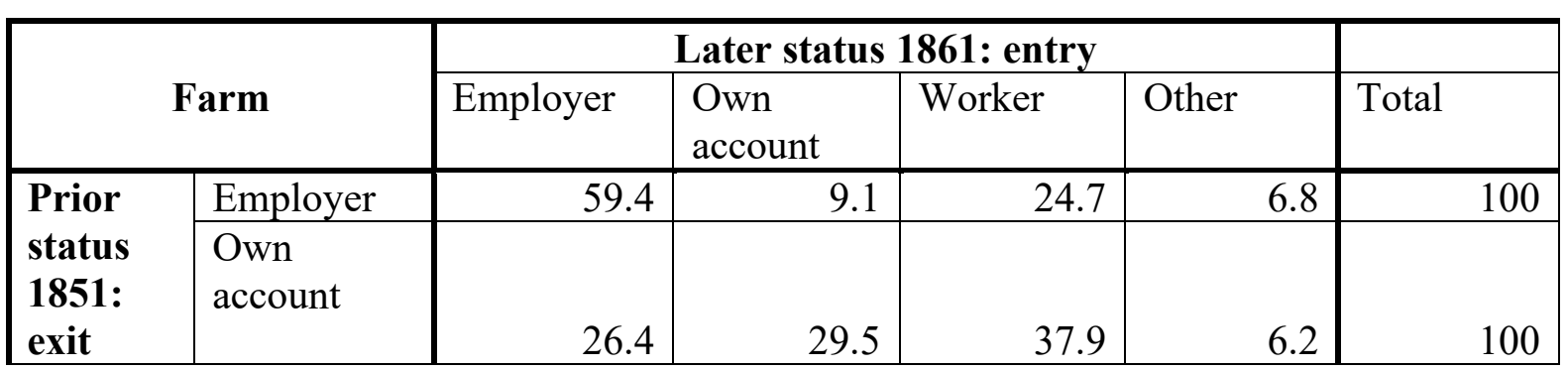

Table 3. Exit percentage from employers or own account in 1851 to other statuses in 1861 (each row sums to 100 percent).

Using the two formats of Tables 2 and 3 we can compare entry and exit over time. In this extension we also divide the tabulations between sexes to reflect the different labour markets involved, but also to allow for possible non-representativeness of the 1871 female non-farm 
linkage. For the following discussion we only attempt indicative interpretations over time; the limitations of 1871 data prevent detailed testing or strong conclusions being drawn. Nevertheless, some important potential indications of trends can be inferred. Figure 1 compares non-farm proprietors; exit percentages (as in Table 2) and entry percentages (as in Table 3 ) are shown side by side for each linked year, then employers and own account are compared, separately by sex. Figure 2 shows the same analysis for farm entry and exit. Apart from the limitations of the 1871 data care needs also to be exercised because female sample sizes are smaller (6.1 percent of all non-farm linked proprietors, and 5.7 percent of farm links).

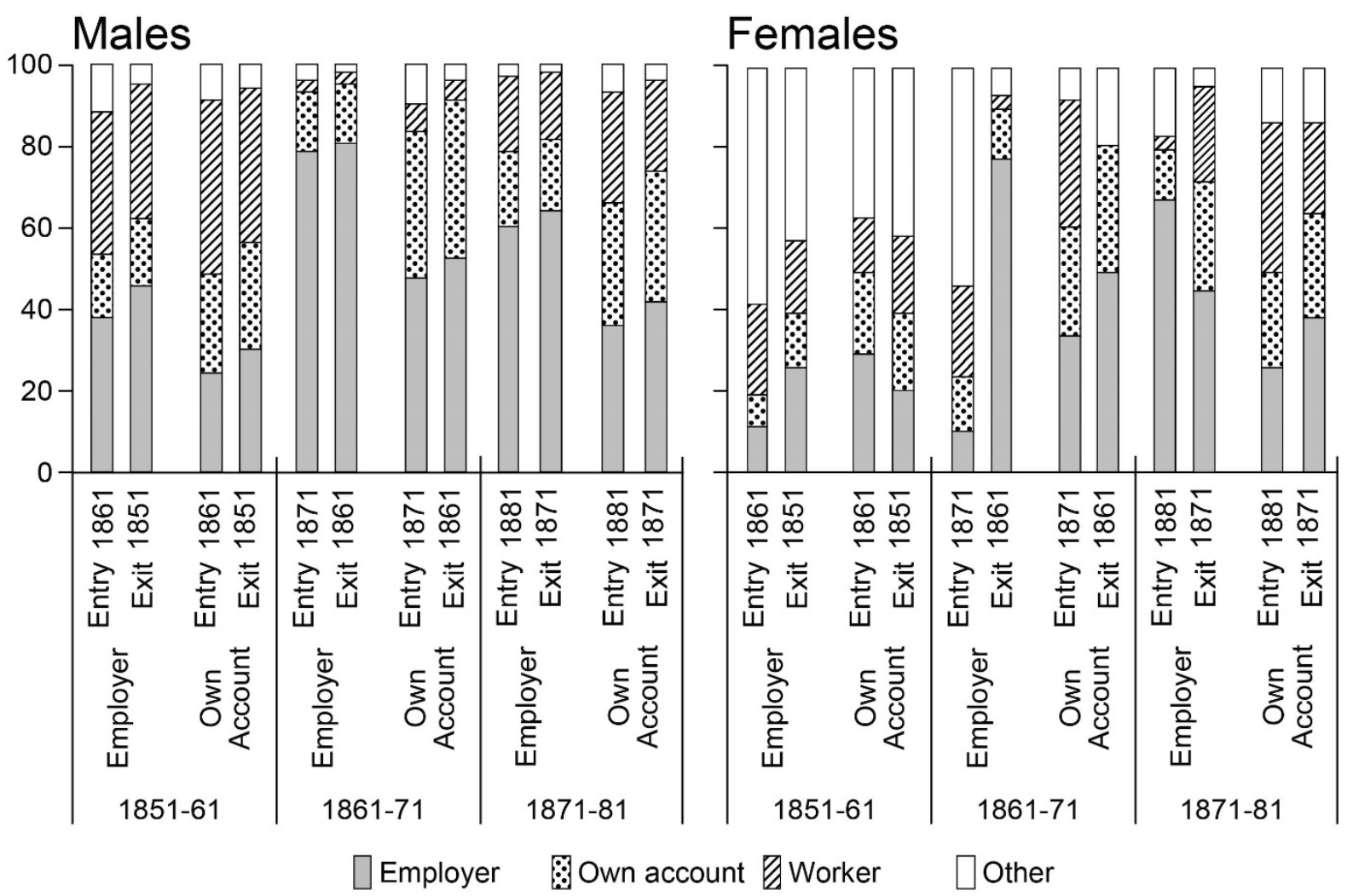

Figure 1. Non-farm proprietor entry and exit

A notable feature of the results is that entry and exit frequencies are quite close in most categories, suggesting similar underlying factors in people's entry and exit decisions. As 
indicated in the previous tables for 1851-61, employers have a higher level of stability than own account, and farmers have higher stability than non-farmers. Stability in these figures is indicated by the section of the bar that has the same status as the column as a whole. Stability (comparing 1851 with 1881) appears to increase over time for both farm and non-farm employers, and applies to both men and women, but stability only slightly increases for nonfarm own-account proprietors. Because of the partial 1871 data, the links of 1861-71 are less reliable as guides (the second group of columns) for exits, and 1871-81 less reliable for entry. Nevertheless, these 1871 links do confirm the broad direction of trends. The trends also show a contrast in the extent to which the major transfers between worker and proprietor status, recognised as important in 1851-61, continued. For the later years the high level of flow into and out of worker status from and to proprietorship is reduced, and there is greater flow between employers and own account. This is particularly true in farming for both genders. The exception for non-farm women, where the worker proportions become larger over time, may reflect the lack of statistical representativeness of this set of female links noted earlier. 


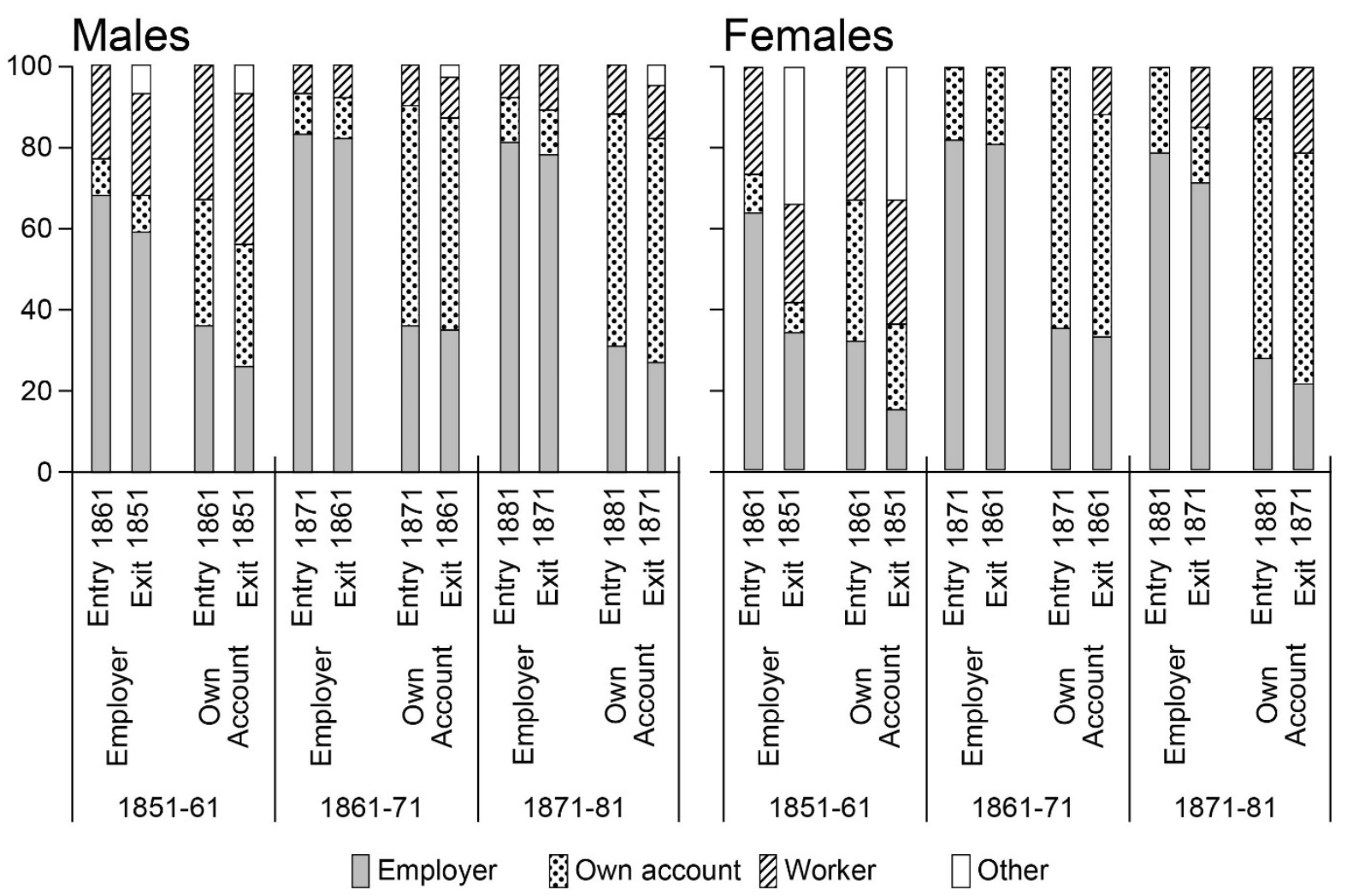

Figure 2. Farm proprietor entry and exit.

In addition to general trends, comparison between the figures allows important observations on differences between the proprietorship experiences of men and women. Indeed, for nonfarm these have the strongest contrasts. As noted earlier, women are much more likely than men to enter and exit proprietorship from/to "other" status. This is to be expected, as the majority of women who were employers were married/widowed and were likely to switch status between economically active and inactive as they dealt with different life-stage challenges (Garrett et al. 2001; Wall 2002; Kay 2009; Davidoff 2012). It also reflects any poorer recording of female economic activity in the census (Higgs and Wilkinson 2016; You 2020a, b). The contrasts between women and men are strongest for non-farm, and generally greater for entry from “other". For 1861 and 1871 entry into employer status, and 1861 own account entry, prior "other" is the largest entry category for non-farm women. For farmers, the reverse tends to occur: that women are more likely to exit to "other", particularly from 1851 
status as either employer and own account. For later years exiting "others" are higher than entry, but the frequencies of both are very small.

\section{Proprietor age}

The census allows considerable scope to assess demographic influences on business evolution. These are more fully investigated below, but an important prior demographic analysis is the role of a person's age. Since we are using combined links, forward and backwards links have the same age distribution except that everyone adds 10 years. The analysis quotes the age at the start of the link. Figure 3 shows age distribution for male non-farmers, comparing those who are stable and do not switch in or out of proprietor status with those that do; those under 15 and over 85 are excluded as a minor part of the data. There is a similar distribution for switchers and non-switchers. However, switchers are older on average, and frequency of switching is slightly lower at younger, and higher at older ages than non-switching (the switcher age distribution is lower and more spread than the non-switcher). This indicates that generally individuals who entered in younger years (25-40) then remained stable only until about 50 on average. Hence, the period of male non-farm proprietorship was often only part of the life cycle and was concentrated in early to middle years. Switching also seems to become slightly more prevalent in older ages over time. However, there was also extensive overlap at all ages. 

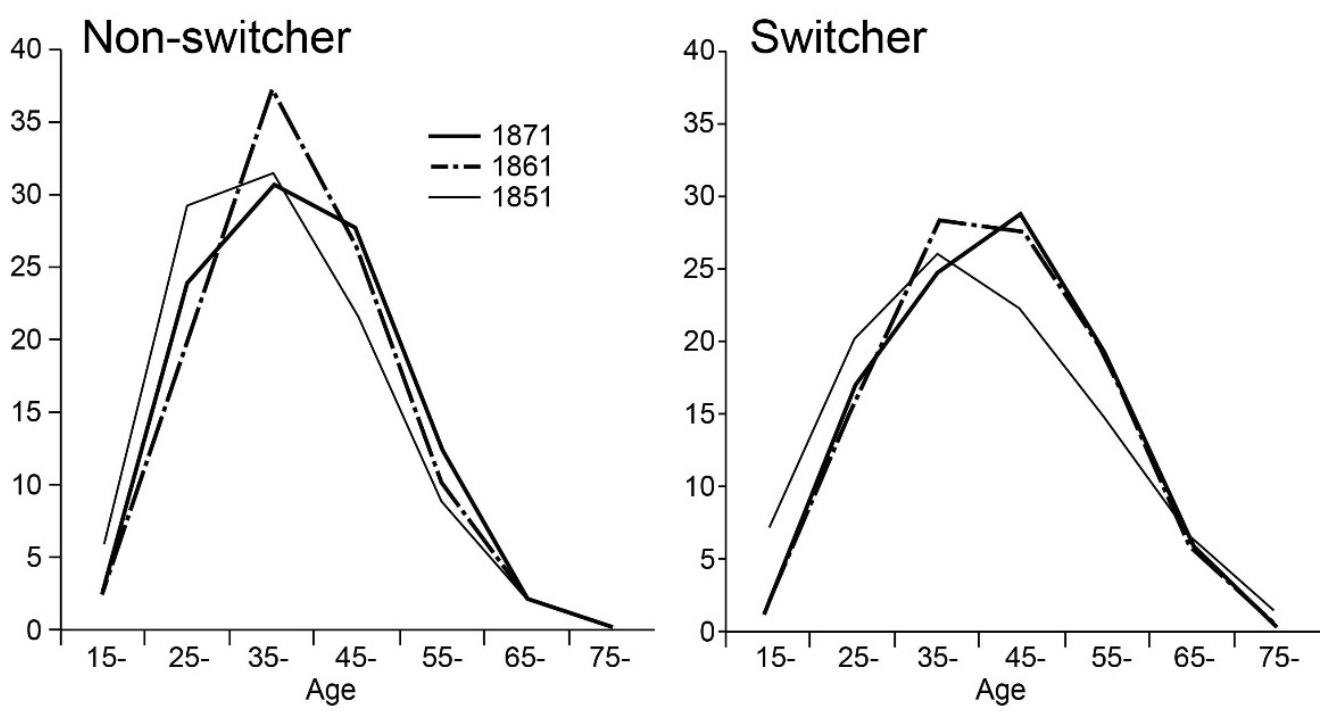

Figure 3 A. Male non-farm proprietor age distribution comparing non-switchers and switchers between status by year.
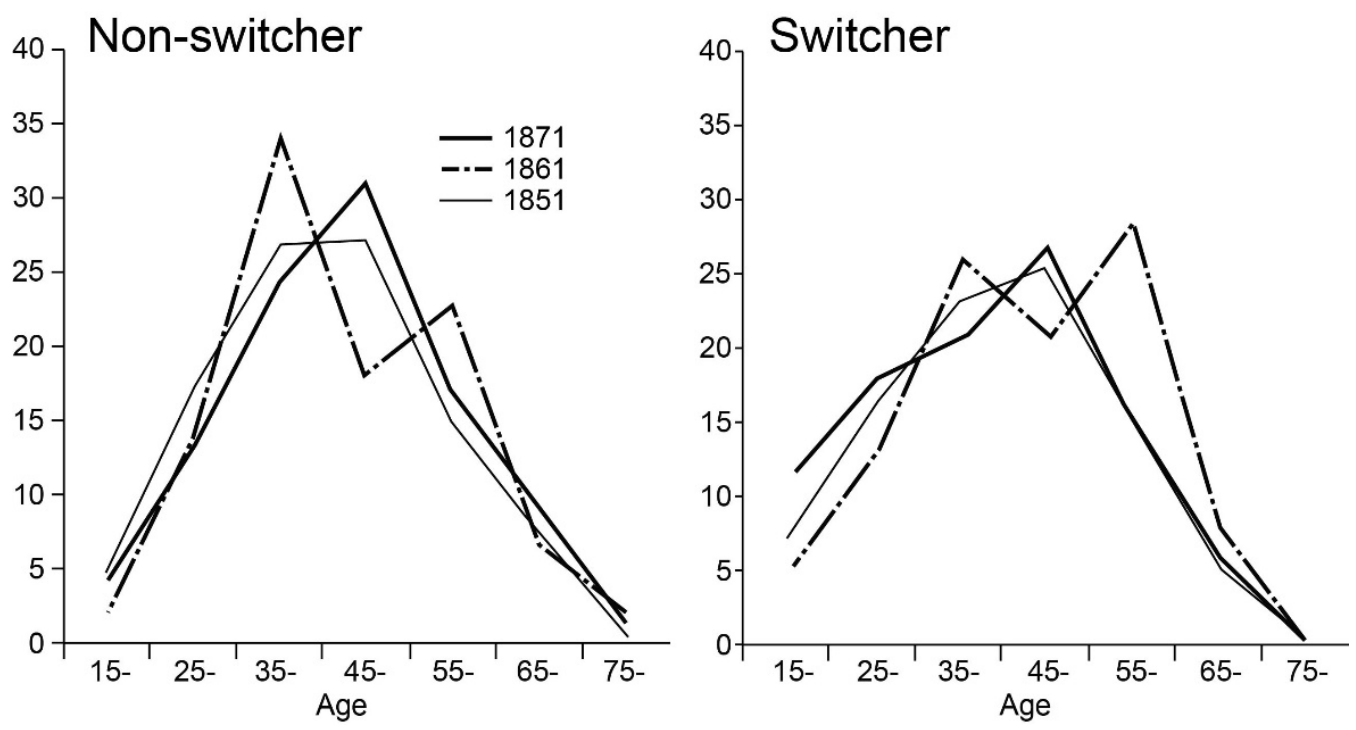

Figure 3 B. Female non-farm proprietor age distribution comparing non-switchers and switchers between status by year.

For non-farm women there is a more varied differentiation across the age range which partly reflects instability from smaller samples in some age categories especially in 1861-71, but also indicates the much more varied life histories of many women (Figure 3 B). Most notable is that 
non-switching women were only slightly younger than switchers, on average. This is a contrast to men. Also switching for women was generally over a wider and higher age-range than men: they entered proprietorship slightly later on average and left older. However, for the very youngest categories there were more women entrants up to the age of about 20 than men. As with men, generally women who entered in younger years (25-35) remained before switching in later years mainly from 35 an upwards, but switching was also more frequent across most age groups than for men: the age distribution was slightly flatter and more spread out than nonswitching and for men. This is indicative of a pattern for women that interrelates with marriage and family commitments, investigated further below.

For farmers (Figure 4), the male patterns are similar to those of non-farm, but the age profile was markedly less peaked around 25-45, mainly as a result of non-switchers being much more frequent in older years than for non-farm; i.e. switching occurred in farming on reaching earlier middle years and continued for more ages than it did in non-farming. This also tended to increase for the later period. For women the pattern is much smoother than for non-farm as the sample size is larger and less varied. Frequencies of female proprietorship in farming were much closer between switchers and non-switchers than males, but the major contrast was the much greater peaking at higher ages of 45-65. This is indicative of wider family interdependencies for women, where they often took on a farm in middle or later years as widows. But the very tight and close alignment of the switchers and non-switchers in the older age ranges shows they were more likely than men to pass on the farm rapidly to others, often family members. The major feature of contrast between farm and non-farm as a whole derived from this older age female proprietor frequency. 

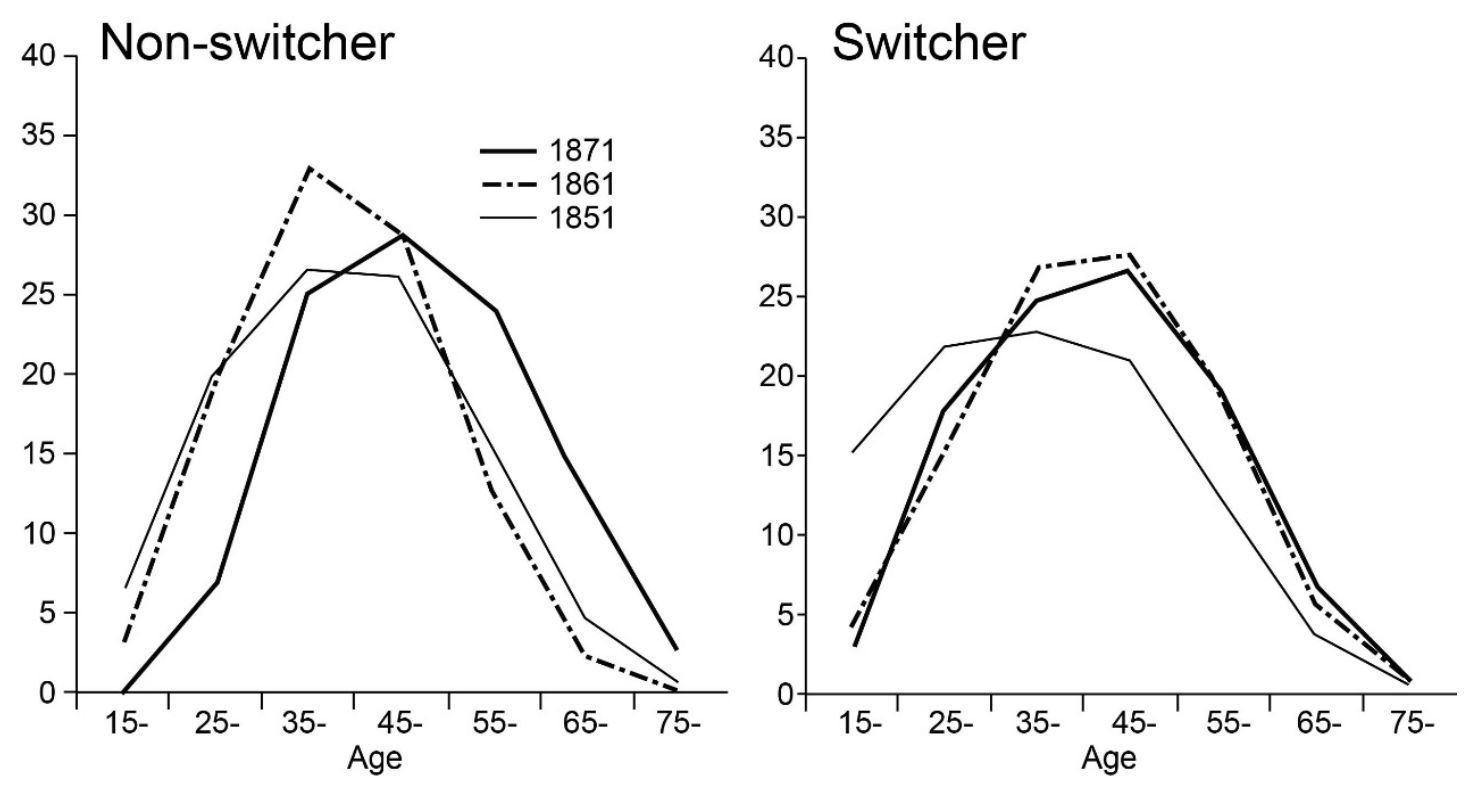

Figure 4 A. Male farm proprietor age distribution comparing non-switchers and switchers between status by year.
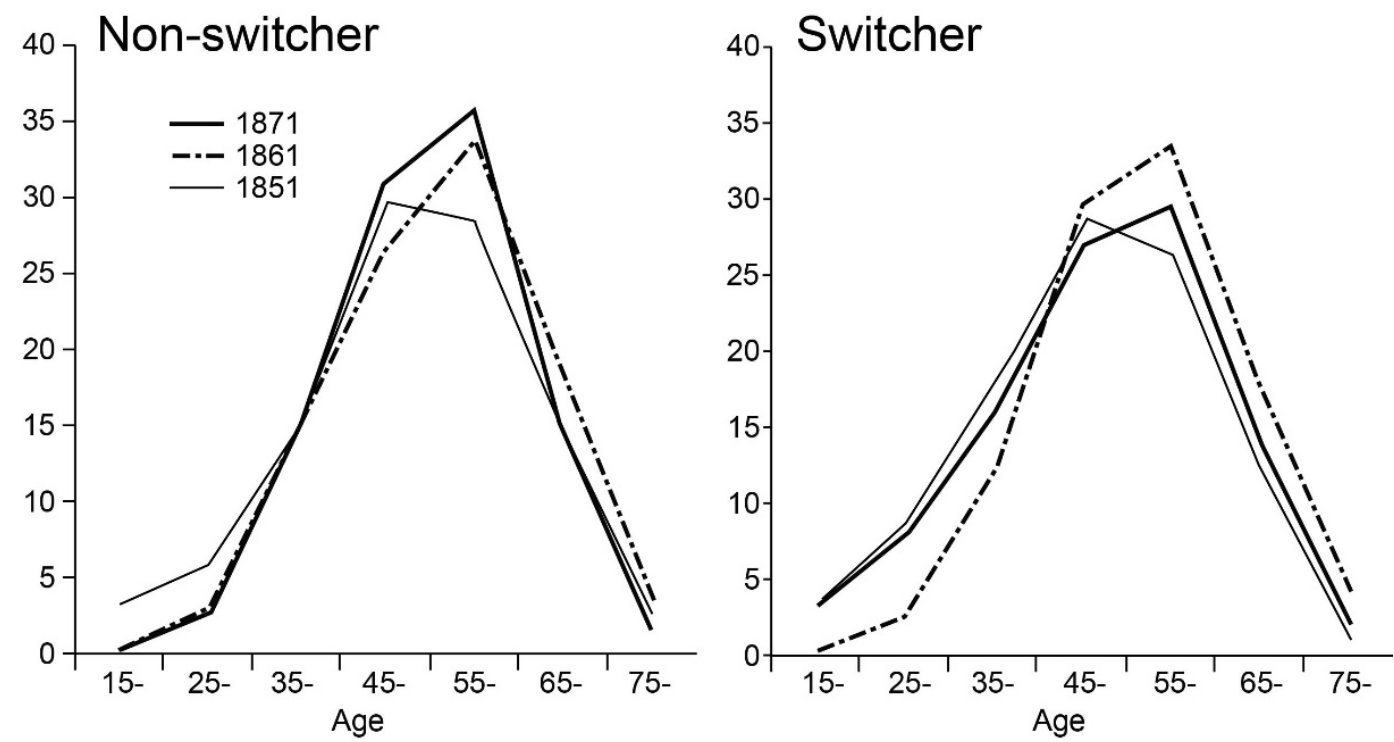

Figure 4 B. Female farm proprietor age distribution comparing non-switchers and switchers between status by year 


\section{Wider covariates}

The analysis is extended to investigate a full range of other variables to assess wider influences on career switches. Because of the constraints of the 1871 data, the estimates are limited here to 1851-61 linkages, which have the strongest data that satisfy the demands of multivariate analysis. However, estimates were also made for all cross-sections of linked years and, while not reported here because of space, they show comparable results.

The dependent variable we seek to understand is the status of different types of proprietor at entry and exit, defined as a categorical variable where an individual has switched or not switched status. This is estimated by a multivariate logit regression. A logit is similar to normal regression but the dependent variable is a category, not continuous. It estimates if an individual has switched status (a value of 1) compared to not switching (a value of zero). This is estimated for each status category (employer and own account) separately, and for entry and exit separately. $\mathrm{P}_{\mathrm{i}}$ is the estimate of a switch of status for each linked individual $\mathrm{i}$ :

$$
\left(P_{i}=1,0\right)=\beta_{0}+\beta_{1} X_{1 i}+\beta_{2} X_{2 i}+\ldots+\beta_{n} X_{n i}+e_{i}
$$

The analysis below estimates the extent to which the series of covariate variables $\mathrm{X}_{1 \mathrm{i}}$ explains the switching or non-switching; $\beta_{0}, \beta_{1} \ldots . \beta_{\mathrm{n}}$ are the estimated coefficients for each variable 1 $\ldots \mathrm{n}$, and $\mathrm{e}_{\mathrm{i}}$ is the random error term. Where the covariates are categories a base category has to be chosen against which the other categories are compared.

From the theoretical discussion we expect key covariate variables to be demographic and social, locational reflecting opportunity and necessity, and sector/occupational. Of the demographic and social variables, age has already been shown to have important distinctions between life-cycle effects on switching/non-switching, with age squared also used to capture nonlinear effects - reflecting the rise and then fall of the general age profile of proprietorship and switching propensity (in Figures 3-4). Other personal demographic variables included are 
all categorical: sex, to estimate different switching frequencies of proprietorship among women; marital status (single, married, widow/er); and relationship of individuals within their household which affects their family and social position (defined at the start of the link). In the census, relationships are defined relative to head, who in a single conjugal unit (CFU of husband, wife and children) is usually the husband; in more complex households this may be the senior male, senior female, or another person who took responsibility for filling in the census form. The head is used as the base case. ${ }^{13}$

Other important covariates estimated relate to location in order to assess the role of local business opportunities and market conditions. As Marshall (1891: 272-3, 286-8) recognised, localisation remained key for small firms, with markets of different sizes and accessibility critical to business opportunities (see also Wilson and Popp, 2003). This is measured by population density, density squared to capture nonlinear effects, and also by an urban/rural coding which distinguishes different sizes and types of town or rural area. Four urban/rural categories are developed from long-established definitions by Law (1967) and Robson (1973); see (Smith and Bennett 2017): Urban - a population of $\geq 10,000$ (the base category); Urban transition - urban fringe areas, namely non-urban parishes in Registration Sub-Districts (RSDs) having at least one urban parish; Transition - higher density RSDs that contained no LawRobson town; Rural - RSDs with low population density. Accessibility beyond the locality is assessed by two railway access variables: distance (kilometres) to the nearest rail station and distance to nearest rail line; lines may be more significant than stations for some businesses because there were many private sidings and drop-off/pick-up points. Business opportunities are expected to decrease as distance to rail increases. However, because by the start of the analysis in 1851 most of the country was accessible to rail, the effects may be small.

\footnotetext{
${ }^{13}$ Relationships are code as RELA in I-CeM (Higgs et al. 2015); these are simplified to a set of 10 main categories here.
} 
A key covariate is expected to be sector market conditions. As recognised by Marshall and Marshall (1879: 117) and Marshall (1891: 284-90), and demonstrated by large scale crosssectional census analysis (Bennett et al. 2019b: 94-99, 142-50), sectors offered differing opportunities to sole traders and established businesses, reflecting their different competitive conditions, extent of market entry barriers, and capital needs. The contemporary census coding, now captured in I-CeM, gives 797 occupation categories (Schürer and Higgs 2014). These only imperfectly match business sectors, as criticised by contemporaries (e.g. Booth 1886) and by modern researchers (e.g. Armstrong 1972). To overcome this, the BBCE database offers a sector coding to 13 business sectors, which are aggregated to be approximately equivalent to an aggregation of modern SICs at 1-digit level. ${ }^{14}$ Non-farm and farm aggregates are estimated separately. The base sector for non-farm is manufacturing, which had one of the lower switching rates for employers.

\section{Non-farm proprietors}

Entry by non-farm employers and own account is compared in Tables 4 and 5. The estimates are developed separately for employers (left columns) and own account proprietorship (right columns), and for entry (Table 4) and exit (Table 5). For entry to being employers in Table 4, age and age squared are highly significant. They capture the rise and then fall in the frequency of being a proprietor and, as expected from Figures 3 and 4, they confirm the strong statistical significance of age as a key factor in switching choices. Among the other demographic variables, being female significantly reduced the level of switching (compared to the male base), whilst being married or widowed significantly increased the frequency of switching (compared to being single), and more so for the widowed than married. These effects confirm

\footnotetext{
14 The detailed classification of contemporary census occupations in I-CeM to aggregate sectors is given in (Bennett et al. 2017; Bennett et al. 2019a), including relation to SIC; with data downloads of definitions for all 797 codes.
} 
the expectations from previous literature that entry was more likely into proprietorship for males, and more likely with the additional established resource support of a spouse. However, with the death of a spouse, entry into business increased even higher, probably as a result of two interacting influences: necessity for income for the survivor, and in many cases the only means of business continuation, especially for the role of widow/ers. In comparison to sex and marital status, the only other significant social or demographic variable is CFU status. Being an offspring of a family unit (compared to the head as base) was strongly negative for switching into proprietorship, confirming that family members were less likely to be the named employer where there was a surviving parent as head. As suggested by Crossick (1978) and Anderson $(1971,1988)$ this could be rather exploitative, holding back offspring who had otherwise no alternative but the leave home, though of course these sons and daughters might eventually take over a business. It is also reflects the fact that it was rare for children to run their own business while living with parents (Smith et al., 2020) and more common to set up their own household. Being an other relatives or non-relative in the household does not appear significant influence on entry; this is a contrast to the wider role played in many family businesses prior to entry as proprietor found by Davidoff (2012), though this was based only on case studies.

\begin{tabular}{|c|c|c|c|c|}
\hline & \multicolumn{2}{|c|}{ Employer entry } & \multicolumn{2}{|c|}{ Own account entry } \\
\hline Age & $0.343^{* * *}$ & $(35.61)$ & $0.256^{* * *}$ & $(15.02)$ \\
\hline $\mathrm{Age}^{2}$ & $-0.002^{* * *}$ & $(-29.89)$ & $-0.002^{* * *}$ & $(-12.66)$ \\
\hline Married & $0.377^{* * *}$ & $(-5.17)$ & $0.450^{* *}$ & (2.99) \\
\hline Widowed & $0.450^{* * *}$ & $(5.08)$ & $0.840^{* * *}$ & $(4.82)$ \\
\hline CFU member & $-0.472^{* * *}$ & $(-3.43)$ & $-0.767^{* *}$ & $(-3.18)$ \\
\hline Older generation & -0.002 & $(-0.01)$ & 0.797 & $(1.80)$ \\
\hline Siblings & -0.123 & $(-0.53)$ & 0.003 & $(0.01)$ \\
\hline Other family & -1.745 & $(-1.62)$ & 0 & (.) \\
\hline Servants & 0 & (.) & 0 & (.) \\
\hline Working title & 0 & (.) & 0 & (.) \\
\hline Lodgers/boarders & -0.556 & $(-1.74)$ & -0.160 & $(-0.37)$ \\
\hline Non-household & 0 & (.) & 0 & (.) \\
\hline Unknown & 0.058 & $(0.15)$ & -0.811 & $(-1.51)$ \\
\hline Female & $-1.416^{* * *}$ & $(-13.92)$ & $-0.895^{* * *}$ & $(-3.79)$ \\
\hline Density RSD & $-0.003^{* * *}$ & $(-3.86)$ & -0.003 & $(-1.63)$ \\
\hline Density RSD ${ }^{2}(000 \mathrm{~s})$ & 0.002 & $(0.62)$ & 0.006 & $(0.85)$ \\
\hline Urban transition & -0.060 & $(-0.69)$ & -0.138 & $(-1.11)$ \\
\hline
\end{tabular}




\begin{tabular}{lllll} 
Transition & 0.01 & $(0.32)$ & 0.065 & $(1.15)$ \\
Rural & -0.0744 & $(-1.63)$ & $-0.281^{* *}$ & $(-3.30)$ \\
\hline Rail line distance & -0.013 & $(-1.51)$ & $0.031^{*}$ & $(2.37)$ \\
Rail station distance & -0.001 & $(-0.10)$ & -0.021 & $(-2.35)$ \\
\hline Mining \& quarrying & 0.094 & $(0.68)$ & -0.007 & $(0.04)$ \\
Construction & $0.095^{*}$ & $(2.29)$ & $-0.341^{* * *}$ & $3.78)$ \\
Maker-dealer & 0.034 & $(0.79)$ & $0.256^{* *}$ & $(3.24)$ \\
Retail & $0.680^{* * *}$ & $(11.00)$ & $0.475^{*}$ & $(2.68)$ \\
Transport & $0.108^{* * *}$ & $(1.35)$ & 0.074 & $(0.54)$ \\
Prof \& bus services & $0.749^{* * *}$ & $(6.12)$ & -1.142 & $(-0.40)$ \\
Personal services & $0.042^{* *}$ & $(0.24)$ & $0.747^{* * *}$ & $(5.40)$ \\
Agric processing & $0.889^{* * *}$ & $(12.91)$ & -0.272 & $(-1.51)$ \\
Food sales & $0.743^{* * *}$ & $(13.75)$ & $0.999^{* * *}$ & $(12.12)$ \\
Refreshment & $0.504^{* * *}$ & $(4.85)$ & 0.511 & $(3.00)$ \\
Finance \& commerce & $0.790^{* * *}$ & $(5.28)$ & 0 & $(-2.18)$ \\
No occupation given & -0.060 & $(-0.58)$ & -0.236 & $(-2.92)$ \\
\hline Constant & $-10.36^{* * *}$ & $(-41.92)$ & $-9.303^{* * *}$ & $(-23.30)$ \\
Observations & 25,588 & & 10,042 & \\
Pseudo R & 0.149 & & 0.131 & \\
\hline
\end{tabular}

Table 4. Logit estimates for entry to being non-farm proprietors 1851-61. Note: coefficients, with z-values in brackets; base categories single, head, male, urban, manufacturing; ${ }^{*} \mathrm{p}<0.05$, $* * \mathrm{p}<0.01, * * * \mathrm{p}<0.001$

Locational opportunity appears from this analysis to have rather restricted influence on nonfarm business entry. There is a strong negative influence of high population density for employers which indicates the powerful effect of waged alternatives in larger and denser locations such as towns and cities which reduced the incentives to establish a business. The broader differences between urban and rural areas were of little significance.

The effect of age on entry to own-account traders was marginally lower than for employers, but married and widowed status had larger effects. This confirms other analyses based on crosssections of the census (Bennett et al. 2019b; van Lieshout et al. 2019), that own account was more accessible at most ages, was particularly available to women, especially married women, and in some sectors offered many more women a route to proprietorship that men, though this was often stimulated by necessity of increasing family income. Switching into own account 
was less likely from being a CFU member; i.e. they usually sought internal support to a family business as employees or wage work elsewhere. There were minor effects of rural context reducing own account market entry, but as with employers opportunity the effects were small.

One of the key aspects of the analysis in Table 4 is the strong contrasts between sectors, and between own account and employers, as expected from Marshall's observations and from previous cross-sectional analysis (Bennett et al 2019b). Employer entry was higher for most sectors than the manufacturing base, indicating significantly more ready market entry into six or seven sectors for employers, and into two or four (depending on significance level) for own account. For employers the service sectors were far more open to entry for those employing others than the manufacturing base. Significant sector effects overlap between own account and employers only for general retail and food sales - the two main retail activities - indicating these had similar entry possibilities at all scales (starting a shop was almost as easy as a sole proprietor as taking on employees, and easier for food sales). Otherwise own account mainly had significantly higher entry for personal services, whereas entry to construction was strongly less likely. These are all comparisons between switching and staying in a current status in that sector. Hence, the absence of switching of status from own account for construction indicates strong stability: these individuals changed status less than own-account manufacturers as there was little alternative in that sector to being own account.

Exits by non-farm employers and own account in Table 5 show some strong contrasts with entry. Age was still strongly significant for employers, but with a much flatter profile over the cohorts: exiting increased less steeply with age than entry (q.v. Figure 3). Own-account exit was not significantly affected by age: it occurred at any point, depending on opportunity/need. Combined with the entry effects, this shows that own account was a more flexible choice, entered with increasing frequency as age increased, but with exits occurring at any time. Marital status was not significant for employer exit, but strongly positive for own account, 
especially for widowed. Thus although entry was high for the widowed, exit was also high suggesting it was often unstable as a career choice, was difficult to sustain the business, and that some were "caretakers" of a business which was passed to others at a later date (Wall 2002; Davidoff 2012). Women had no significant differences of exiting frequency compared to men. This is an important contrast with market entry. It supports the arguments that women suffered barriers to accessing occupations, but once in them their profile of experience differed little from men (Nenadic 1991; Davidoff 2012; Kay 2009; Aston and Bishop 2020): business was business whatever the sex of the proprietor, as supported by modern analysis (Marlowe et al. 2009). More relationships within the household were significant for exit. For employers, CFU status, sibling, boarder and working title were all significantly less likely as categories for a proprietor to exit into than remaining as head. "Working title" is the I-CeM term for being an employee or assistant in the family business: proprietors were very unlikely to exit into such positions.

\begin{tabular}{lllll}
\hline & Employer exits & \multicolumn{2}{l}{ Own account exits } \\
\hline Age & $0.035^{* * *}$ & $(3.66)$ & -0.006 & $(-0.37)$ \\
Age $^{2}$ & $-0.001^{* * *}$ & $(-4.59)$ & 0.000 & $(1.40)$ \\
\hline Married & -0.073 & $(-1.14)$ & $0.269^{*}$ & $(2.15)$ \\
Widowed & -0.015 & $(-0.17)$ & $0.949^{* * *}$ & $(5.83)$ \\
\hline CFU member & $-0.276^{* *}$ & $(-3.04)$ & -1.312 & $(-1.18)$ \\
Older generation & -0.084 & $(-0.08)$ & $-0.988^{*}$ & $(-2.15)$ \\
Siblings & $-0.424^{*}$ & $(-2.04)$ & 0.283 & $(0.60)$ \\
Other family & -0.663 & $(-1.86)$ & 0 & $()$. \\
Servants & -0.472 & $(-0.47)$ & 0 & $()$. \\
Working title & $-2.063^{* *}$ & $(-2.62)$ & 0.145 & $(0.55)$ \\
Lodgers/boarders & $-0.772^{* *}$ & $(-2.80)$ & 0 & $()$. \\
Non-household & 0 & $()$. & -0.162 & $(-0.42)$ \\
Unknown & -0.186 & $(-0.60)$ & 0.312 & $(0.93)$ \\
\hline Female & -0.051 & $(-0.42)$ & 0.303 & $(0.58)$ \\
\hline Density RSD & -0.001 & $(-1.33)$ & $-0.004^{* *}$ & $(-2.64)$ \\
Density RSD $(000 \mathrm{~s})$ & 0.001 & $(0.20)$ & 0.00194 & $(0.29)$ \\
\hline Urban transition & -0.134 & $(-1.38)$ & -0.140 & $(-0.70)$ \\
Transition & -0.066 & $(-1.58)$ & $0.176^{*}$ & $(2.12)$ \\
Rural & $-0.272^{* * *}$ & $(-5.84)$ & $0.295^{* * *}$ & $(3.49)$ \\
\hline Rail line distance & 0.008 & $(1.12)$ & -0.007 & $(-0.54)$
\end{tabular}




\begin{tabular}{lllll} 
Rail station distance & -0.009 & $(-1.37)$ & 0.006 & $(0.43)$ \\
\hline Mining \& quarrying & -0.035 & $(-0.21)$ & 0.407 & $(1.33)$ \\
Construction & $-0.165^{* * *}$ & $(-3.58)$ & $-0.222^{*}$ & $(-2.33)$ \\
Maker-dealer & $-0.539^{* * *}$ & $(-11.94)$ & -0.082 & $(-0.99)$ \\
Retail & $0.410^{* * *}$ & $(5.56)$ & -0.062 & $(-0.28)$ \\
Transport & $0.250^{*}$ & $(2.20)$ & 0.212 & $(0.54)$ \\
Prof \& bus services & $0.967^{* * *}$ & $(5.20)$ & -1.155 & $(-0.99)$ \\
Personal services & $-0.373^{*}$ & $(-2.25)$ & $1.485^{* * *}$ & $(6.30)$ \\
Agric processing & $0.379^{* * *}$ & $(5.37)$ & 0.052 & $(0.29)$ \\
Food sales & 0.050 & $(0.93)$ & $1.141^{* * *}$ & $(11.18)$ \\
Refreshment & $0.313^{*}$ & $(2.55)$ & $1.410^{* *}$ & $(2.78)$ \\
Finance \& commerce & $0.948^{* * *}$ & $(4.00)$ & 0 & $()$. \\
No occupation given & 0.166 & $(1.15)$ & $-1.203^{*}$ & $(-1.96)$ \\
\hline Constant & 0.063 & $(0.30)$ & $-1.617^{* * *}$ & $(-4.47)$ \\
\hline Observations & 18,509 & & 7,122 & \\
Pseudo R & 0.026 & & 0.046 & \\
\hline
\end{tabular}

Table 5. Logit estimates for exit from being non-farm proprietors 1851-61. Notes: as Table 4.

Locational opportunity generally played a minor role on exit as it did on entry, with no rail access effects significant. Density effects, which indicate different opportunities from greater or lesser locally concentrated markets negatively affected own account exit. As to be expected small businesses were more sustainable where there was larger market potential. This was the converse of rurality which increased own-account exiting as the markets were smaller and generally being eroded by the expansion of larger firms. Employer exits, however, were reduced by rurality; once established a rural business that was significant enough to employ others tended to be sustainable and reduced the scope for others to enter, particularly small own-account traders. This indicates some effects of local monopolies as suggested by Marshall, with the lack of rail effects confirming that accessibility did not create significant pressures to exit.

Sector effects were important and contrasting. Employer exits were more frequent and higher than manufacturing in four sectors, but less in three. Own-account exits were strongly significant and positive in only three. It is important to note that own account had higher 
positive exit significance than employers in personal services, indicting increasing competition from larger enterprises in activities such as laundries, hairdressing, doctors and school proprietorship. This is also suggested in maker-dealing where the coefficient is much higher for continued trading for employers than for own account. This confirms Marshall's (1891: 288) view that whilst the small manufacturer of shoes, dress and other items who also retailed continued to survive; they were under increasing pressure from larger manufacturers and retail branch networks.

The logit estimates are important confirmation of previous analysis at aggregate sector level that has not had the benefit of individual career tracking (e.g. Clapham 1932; Checkland 1964; Lee 1971, 1981). Sectors such as refreshments, maker-dealing, retailing, and personal services, which had very low entry costs and barriers, all show high entry rates compared to manufacturing, for both employers and own account. They also had a high and rapidly increasing share of employment and businesses (Lee 1971: 60-6; Bennett et al. 2019b: 94-100, 2021). Sectors with high exit costs, low elasticity, or high sunk capital and skills, had higher stability or inertia from incumbency. These were mainly in manufacturing which usually had plant and physical investment, so that few sectors had lower exit levels than the manufacturing base. Those that did have significantly lower employer exits were maker-dealers, personal services and construction. This reflected rapid expansion responding to population growth even though there were structural shifts of sector growth towards large manufacturers and retail networks; i.e. as Marshall observed, the maker dealer and many small firms could survive whilst nevertheless experiencing increasing competition.

\section{Farm proprietors}

Farm proprietorship was rapidly shedding labour through the impact of major technological 
changes, accelerated by the agricultural depression of the 1870s. Over 1851-61, covered by the Table 6 record linkage, farm employer numbers were almost static, but own account increased (Montebruno et al. 2019). Entry for both types of proprietor had similar demographic effects, though lower coefficients, than for non-farm. Married and widowed status again had much higher entry than single people (though slightly lower than non-farm), with women having much lower rates (and much lower than non-farm). Hence, as expected from the stable employer numbers, high levels of incumbency and challenging conditions for farming, market entry was generally less attractive and more difficult than non-farm, and especially for women (as also shown in Figures 1-2). As a result, as to be expected, household members generally had significantly lower farm entry rates than non-farm employers, with the comparable CFU entry very much lower.

Locational opportunity was generally much more significant for farm market entry than nonfarm, which shows that the effects of urban expansion and improved rail access were mainly influencing farming business opportunities. Entry fell as population density fell, as expected, but for employers this was only marginal compared to the significantly higher entry rates for all areas than the urban base. This reflects the fact that farms were being squeezed out of the remaining spaces within urban areas, but were buoyed by the rising population demands in all other situations. Both types of transitional areas were within direct market access of towns by horse and cart, so that direct selling from farm to consumer increased with urbanisation, especially in dairy produce (Winstanley 1996; Schwartz 2010). Rail was also making many remoter rural areas accessible through milk trains, cattle wagons, increasingly sophisticated rail collection centres, and expanded wholesale facilities (Simmons 1986; Schwartz 2010). However, rail distance itself though not significant for employers, was highly significant for own account entry. This worked both ways, favouring entry to farms that were remoter from lines, and reducing farm entry where there was a station because of increased competition from 
other sectors of activity, as indicated for refreshments by Simmons (1986) and Davidoff(1995), and for agricultural processing by Clapham (1932) and Checkland (1964).

\begin{tabular}{lllll}
\hline & Employer entry & \multicolumn{2}{l}{ Own account entry } \\
\hline Age & $0.272^{* * *}$ & $(45.83)$ & $0.202^{* * *}$ & $(13.29)$ \\
Age $^{2}$ & $-0.002^{* * *}$ & $(-36.36)$ & $-0.001^{* * *}$ & $(-11.01)$ \\
\hline Married & $0.329^{* * *}$ & $(8.13)$ & $0.451^{* * * *}$ & $(3.81)$ \\
Widowed & $0.380^{* * *}$ & $(6.98)$ & $0.466^{* * *}$ & $(3.41)$ \\
\hline CFU member & $-1.185^{* * *}$ & $(-8.61)$ & & \\
Older generation & $-1.01^{*}$ & $(-2.14)$ & -0.424 & $(-1.24)$ \\
Siblings & $-1.387^{* * *}$ & $(-5.13)$ & 0.0877 & $(0.07)$ \\
Other family & -0.876 & $(-1.77)$ & -1.722 & $(-1.67)$ \\
Servants & 0 & $()$. & 0 & $()$. \\
Working title & -0.107 & $(-0.10)$ & 0 & $()$. \\
Lodgers/boarders & $-1.504^{* * *}$ & $(-3.37)$ & & \\
Non-household & 0 & $()$. & -0.104 & $(-0.12)$ \\
Unknown & -0.148 & $(-0.39)$ & 0 & $()$. \\
\hline Female & $-1.961^{* * *}$ & $(-34.84)$ & $-1.138^{* * *}$ & $(-9.78)$ \\
\hline Density RSD & $-0.008^{* *}$ & $(-2.55)$ & $-0.048^{* * *}$ & $(-2.91)$ \\
Density RSD ${ }^{2}(000 \mathrm{~s})$ & 0.024 & $(1.70)$ & $0.000^{* *}$ & $(2.90)$ \\
\hline Urban transition & $0.437^{* * *}$ & $(5.80)$ & -0.068 & $(-0.48)$ \\
Transition & $0.346^{* * *}$ & $(5.62)$ & -0.010 & $(-0.09)$ \\
Rural & $0.433^{* * *}$ & $(7.07)$ & 0.005 & $(0.04)$ \\
\hline Rail line distance & -0.008 & $(-1.68)$ & $0.072^{* * *}$ & $(6.11)$ \\
Rail station distance & $0.009^{* *}$ & $(2.14)$ & $-0.047^{* * *}$ & $(-4.34)$ \\
\hline Constant & $-8.644^{* * * *}$ & $(-52.19)$ & $-7.750^{* * *}$ & $(-17.44)$ \\
\hline Observations & 43,026 & & 9,288 & \\
Pseudo R & 0.168 & & 0.075 & \\
\hline
\end{tabular}

Table 6. Logit estimates for entry to being farm proprietors 1851-61. Notes: as Table 4.

Exit from farm proprietorship was generally influenced by the same factors as entry, as shown in Table 7, though age was now mostly insignificant, married status favoured incumbency, and females once into farm proprietorship were much less likely to leave than men (q.v. figure 4). Locational effects were generally in the opposite direction to entry, indicating higher entry but lower exit rates for employers in denser areas, and in transition and rural areas than urban. Proximity to rail lines increased employer exit, whereas stations reduced exit. If a farm was 
still viable improved access often increased its income by diversification into a portfolio of business activities, of which accommodation, refreshments and carriage were easy options for most farms using their existing buildings and carts (Winstanley 1996; Schwartz 2010; Radicic et al. 2017).

\begin{tabular}{lllll}
\hline & Employer exits & \multicolumn{3}{l}{ Own account exits } \\
\hline Age & 0.012 & $(1.77)$ & 0.013 & $(0.64)$ \\
Age $^{2}$ & $-0.000^{*}$ & $(-2.21)$ & -0.000 & $(-0.21)$ \\
\hline Married & $-0.197^{* * *}$ & $(-4.43)$ & 0.067 & $(0.47)$ \\
Widowed & -0.107 & $(-1.56)$ & 0.001 & $(0.01)$ \\
\hline CFU member & $-0.613^{* * *}$ & $(-6.84)$ & $-0.643^{*}$ & $(-2.33)$ \\
Older generation & -1.003 & $(-1.00)$ & 0 & $()$. \\
Siblings & $-1.112^{* * *}$ & $(-5.61)$ & -0.595 & $(-0.95)$ \\
Other family & $-0.636^{*}$ & $(-2.00)$ & 0 & $()$. \\
Servants & $-1.552^{*}$ & $(-2.39)$ & & \\
Lodgers/boarders & -0.525 & $(-1.71)$ & & \\
Working title & 0 & $()$. & 0.437 & $(0.64)$ \\
Non-household & 0.300 & $(1.08)$ & & \\
Unknown & $-0.613^{* * *}$ & $(-6.84)$ & -0.441 & $(-0.36)$ \\
\hline Female & $-0.465^{* * *}$ & $(-5.94)$ & 0.158 & $(0.83)$ \\
\hline Density RSD & $-0.019^{* *}$ & $(-2.74)$ & 0.054 & $(1.12)$ \\
Density RSD ${ }^{2}(000 \mathrm{~s})$ & 0.056 & $(1.66)$ & -0.002 & $(-1.44)$ \\
\hline Urban transition & $0.438^{* * *}$ & $(4.54)$ & -0.287 & $(-1.22)$ \\
Transition & $0.630^{* * *}$ & $(7.98)$ & -0.124 & $(-0.66)$ \\
Rural & $0.661^{* * *}$ & $(8.41)$ & $-0.465^{*}$ & $(-2.35)$ \\
\hline Rail line distance & $0.011^{*}$ & $(2.52)$ & $0.043^{*}$ & $(2.08)$ \\
Rail station distance & $-0.016^{* * *}$ & $(-3.97)$ & -0.029 & $(-1.43)$ \\
\hline Constant & $0.399^{*}$ & $(2.21)$ & -0.384 & $(-0.72)$ \\
\hline Observations & 29,228 & & 3,259 & \\
Pseudo R & 0.009 & & 0.015 & \\
\hline
\end{tabular}

Table 7. Logit estimates for exit from being farm proprietors 1851-61. Notes: as Table 4.

Because of the limitations of the 1871 data, we have focused on 1851-61 which has the fullest data linkages. However, this can be tested for robustness against the broader linkage data for the whole period $1851-81$ as a longitudinal cross-sectional time-series, reported in the Appendix for panel estimation. This tracks the same variables over time allowing joint estimation for all periods. It allows whole-period 1851-81 estimation which can confirm the 
persistence of the same explanatory factors of proprietor choice we have estimated for the one period 1851-61. The results are very similar to those reported above for all the same variables that can be included in the panel estimates. This confirms the robustness of the 1851-61 results, and their broad applicability to the whole period.

Further checks of robustness were made by estimating cross-sections for all years, and with solely the tagged data compared with the combined tagged and fully supplemented results shown in Tables4-7. These are not reported because of limited space, but were fully consistent in coefficient signs and most significance levels for all estimates made. Thus, although we have focused mainly on the 1851-61 links, and the fully supplemented data, they appear to be representative of all links for the period. However the limitations of the 1871 data prevent strong inferences on time trends. The overall significance of the various estimates is relatively low (from pseudo $\mathrm{R}^{2}$ ), which was expected because of the high variance in the data due chiefly to respondent sector reporting, as well as any defects of non-response supplementation. The robustness checks confirm that despite high variance, consistent estimation is possible that allows reasonably firm conclusions across the whole period 1851-81.

\section{Conclusion}

This paper has shown the potential for linkage between the digital records of the nineteenth century British censuses using the I-CeM, and the BBCE database of the proprietor population. This allows us to demonstrate that the British Victorian economy of this period was broadly accessible and open to those seeking proprietorship opportunities. Although interpretations are constrained by the ten-year gaps between censuses, switching into and out of proprietorship from worker status appears to have been frequent and possible in many sectors. For example, over the ten years 1851-61 for the non-farm sectors, 36 percent of employers had entered from worker status, and 15 per cent from own account; entries into own account were 43 percent 
from workers. Incumbency and inertia was also high: 37 percent of employers and 25 percent of own-account proprietors were in that same status 10 years earlier (51 percent for combined proprietorship incumbency, with 49 percent switching in/out of proprietorship). Farm incumbency was even higher: 69 percent for employers and 32 percent for own account (75 percent combined, with 25 percent switching in/out of proprietorship). There is some evidence of a "ladder" between worker to own account to employer status, but moving directly into employment from worker status was as frequent or more frequent than from own account. Similarly, the evidence of a progressive disengagement from employer to own account to worker before retirement appears to be a minor aspect of career changes.

The new estimates also allow the dynamism of the Victorian economy to be compared for the first time with modern entry rates to self-employment. Combined employer and own account entry was only 2-3 percent per year in 1990s Britain (Parker 2012: 40-52). This equates to about 25 percent for decadal changes (assuming no compounding), far lower than the 49 percent switching found into non-farm sectors in the $1850 \mathrm{~s}-1860 \mathrm{~s}$. The relative openness of Victorian entrepreneurship echoes Marshall's (1919: 92-3) observation that the mid-nineteenth century had "an unprecedented combination of advantages [that] enabled businessmen to make money even when they were not throwing themselves with energy" into their business. It also confirms Cain and Hopkins' (1993) view that the period analysed covered one of the highpoints of the British economy. Our results present a picture of a more economically open economy than suggested by Miles (1999) or Mitch (1993). We broadly confirm Long's (2013) study, also based on record linkage, of a 'surprising' level of social mobility in Victorian Britain. The high proportion of people moving in and out of employer status also suggests that Morris' (2005) suggestion that stable middle-class lifestyles was the preserve of a small elite that applied only to the largest and most wealthy employers should be revised; however, for many, such status was indeed relatively short-lived, especially for the own account; as Morris notes the opportunities to cement that position through capital accumulation were often slim. Indeed 
own-account proprietorship is confirmed as a relatively ephemeral and short-lived career step for many, often later in life (especially for women), but offering important opportunities to expand family income, particularly among married women and the widowed.

This paper also demonstrates that the main motivations for entering self-employment were closely aligned with those found for modern entrepreneurship, indicating important continuities over time that have never before been open to comment. Internal motivations deriving from demography were an important element of career change in the 19th century, reflecting their first ranked frequency in modern analysis. Age as a surrogate for life-cycle effects was particularly important, showing a clear career progression to more frequent levels of proprietorship up to middle years and then declining in later life. Married and widowed individuals were more likely to enter and less likely to exit proprietorship than single people who were mainly waged. Sex was very important in restricting women's entry, spreading entry over a wider range of years with a degree or irregularity; but sex was not significant on exit, as agued in many smaller scale studies of female entrepreneurship (e.g. Nenadic 1991, 1993; Kay 2009; Davidoff 1995, 2012; Aston 2016). An important finding is that once into business, women's proprietorship development in the 19th century was similar to men's with no significant differences in exit frequencies, once other variables (particularly sector) are taken into account. This reflects women's modern business experiences (Marlowe et al. 2009). Support of family was also a key feature, but CFU position as an offspring generally reduced the frequency of entry. This gives some evidence of the potentially exploitative effects of the family observed by Crossick (1978) and Anderson (1971); many individuals had to wait a long time to take over the proprietorship of their parents' business.

Sector was generally the next most significant aspect of career changes after age, which echoes its third-ranked frequency in modern surveys, and it critical importance observed in crosssectional analysis (Bennett et al. 2019b: 142-50). Contrasts between sectors generally reflect 
expected effects of entry barriers and the benefits of incumbency. Compared to manufacturing most sectors had easier market entry for employers because much lower levels of capital and start-up costs were required; particularly retail, professional services, agricultural processing, food sales, refreshment, and finance and commerce. However, for own account, easier market entry was mainly limited to retail, food, and personal services. Exits show some effects of large firm incumbency and growth. For example, own-account proprietors had higher exit significance than employers in personal services, indicting increasing competition from larger enterprises, whilst in maker-dealing there were similar but much smaller negative effects. Whilst small maker-dealers were under increasing pressure from larger firms, they continued to survive in this period, as Marshall argued. It was in later editions of his 1891 text that Marshall (1920) changed his view that competition was displacing more of these smaller maker-dealers, as taken up by Chandler (1962): when economies from mechanisation of stitching and stamping offered scale effects to large firms that were difficult to match by small local crafts.

Examples of Marshall's contemporary observations on maker-dealers and small traders are numerous. George Beken, a saddle and harness maker in the growing medium-sized town Ashford, Kent (population 8,230 in 1861, 12,369 in 1881), increased his business from one apprentice in 1861 when he was 29, to 2 men in 1871, and 3 apprentices in 1881. Saddle manufacture was one of the lowest profit businesses of the time, but was still relatively immune from machine competition. Joseph Blacker in Emley village in the West Riding was a joiner employing 1 boy (presumably his son) in 1861 when aged 41, employed 1 man in 1871, and had expanded to 2 men, 1 boy and added a small farm of 11.5 acres in 1881 when he was 61 ; he expanded and diversified as opportunity offered in a large but relatively remote village (population 1,406 in 1881) where he commanded a virtual monopoly on joinery. Similarly, John Pleass a carpenter of Cheddon Fitzpaine, Somerset, own account in 1861, employed one man and one boy in 1871 , and reverted to own account in 1881, adapting as his family and 
other circumstances demanded in a relatively buoyant village of 295 people in the expanding fringe of the town of Taunton (population 16,614 in 1881).

Opportunity, and its converse, necessity for entering self-employment, are of course reflected in sector and internal variables, but have been mainly measured in this analysis through location. This shows that population density significantly reduced entry in locally concentrated markets where alterative waged employment was readily available, but differences in urban, rural and transitional locations were only partly significant for non-farm sectors. Differences in access to rail lines and stations also provided only marginal opportunities for non-farm business entry. However, for farm businesses, density, and urban-rural contrasts were all highly significant for employer entry and incumbency/exit. They were only marginal significant for own account, however; except that, in contrast to employers, rail access was more important for own account usually negatively - by increasing competition and reducing business potential. Exits from employer status, and some estimates from own account, indicate that once established many businesses were significant enough to limit access for others though effects of local monopoly, particularly in more rural areas.

The relatively small effects for rail, and its main influence being for farms, confirms the findings by Simmons (1986) and Schwartz (2010) that by 1851 most of the country was sufficiently accessible that business impacts mainly derived from technical and managerial improvement to rail rather than access to lines: new waggons, and specific services for farm products such as development of collection sites. Hence, although Britain was becoming an integrated market, we confirm the observations by Marshall $(1891)$, Lee $(1971,1981)$ and Crafts and Mulatu (2005) that some important local market barriers/monopolies continued, especially for farm businesses.

This paper focuses on linkage to give a whole-population overview, but the deposited database of all business proprietors, and separate downloads of the linked individuals, can be used for 
more detailed case studies and expanded to investigate beyond first-order linkage to wider family and social networks. The results here indicate a level of mobility between employment statuses in the nineteenth century which offers a rich field for further study.

\section{Appendix: Panel estimates}

The appendix reports random-effects logit regression panel estimates which are used to confirm the two-census linkages for 1851-61 estimates in Tables 4-7. The estimates make clear that the covariates influenced proprietor choices in the same directions and similar significance levels as the 1851-61 estimates of Tables 4-7, which can thus be judged broadly representative.

Table A.1 gives the panel estimates for non-farm proprietors and Table A.2 for farmers.

\begin{tabular}{|c|c|c|c|c|}
\hline & Employers & & Own acco & \\
\hline Age & $0.257^{* * *}$ & $(30.55)$ & $0.177^{* * *}$ & $(7.98)$ \\
\hline $\mathrm{Age}^{2}$ & $-0.002^{* * *}$ & $(-27.25)$ & $-0.001^{* * *}$ & $(-7.60)$ \\
\hline Density RSD & $-0.003^{* * *}$ & $(-4.07)$ & $-0.005^{* *}$ & $(-2.97)$ \\
\hline Density RSD ${ }^{2}(000 s)$ & $0.011^{* *}$ & $(3.12)$ & $0.018^{* *}$ & $(2.63)$ \\
\hline Married & $0.231^{* * *}$ & $(3.54)$ & $0.381^{* *}$ & $(2.89)$ \\
\hline Widowed & $0.338^{* * *}$ & $(4.41)$ & $0.717^{* * *}$ & $(4.71)$ \\
\hline CFU member & $-0.569^{* * *}$ & $(-4.42)$ & $-0.992^{* * *}$ & $(-4.65)$ \\
\hline Older generation & -0.069 & $(-0.22)$ & $0.677^{*}$ & (2.19) \\
\hline Siblings & -0.098 & $(-0.48)$ & -0.139 & $(-0.37)$ \\
\hline Other family & -0.718 & $(-1.13)$ & 0 & (.) \\
\hline Servants & 0 & (.) & 0 & (.) \\
\hline Working title & 0 & (.) & 0 & (.) \\
\hline Lodgers/boarders & -0.430 & $(-1.62)$ & -0.694 & $(-1.54)$ \\
\hline Non-household & 0 & (.) & 0 & (.) \\
\hline Unknown & 0.275 & $(0.93)$ & -0.764 & $(-1.75)$ \\
\hline Female & $-0.901^{* * *}$ & $(-9.83)$ & $-0.321^{*}$ & $-(2.56)$ \\
\hline Urban transition & $-0.201^{* *}$ & $(-2.83)$ & -0.095 & $(-0.74)$ \\
\hline Transition & $0.144^{* * *}$ & $(4.40)$ & $0.242^{* * *}$ & $(3.65)$ \\
\hline Rural & 0.051 & $(1.33)$ & $0.366^{* * *}$ & $(4.87)$ \\
\hline Rail line distance & $-0.016^{*}$ & $(-2.10)$ & $0.031^{*}$ & $(2.52)$ \\
\hline Rail station distance & $0.045^{* * *}$ & $(6.66)$ & 0.001 & $(0.18)$ \\
\hline Mining \& quarrying & 0.126 & $(1.10)$ & 0.229 & $(0.90)$ \\
\hline Construction & -0.018 & $(-0.51)$ & $-0.238^{* *}$ & $(-2.69)$ \\
\hline Maker-dealer & 0.051 & $(1.33)$ & $0.282^{* * *}$ & $(3.66)$ \\
\hline Retail & $0.255^{* * *}$ & $(5.10)$ & 0.095 & $(0.88)$ \\
\hline Transport & -0.042 & $(-0.67)$ & $-0.540^{*}$ & $(-2.08)$ \\
\hline Prof \& bus services & $0.774^{* * *}$ & $(8.42)$ & -0.281 & $(-1.46)$ \\
\hline Personal services & -0.170 & $(-1.11)$ & $0.501^{* * *}$ & $(3.55)$ \\
\hline
\end{tabular}




\begin{tabular}{lllll} 
Agric produce processing \& dealing & $0.647^{* * *}$ & $(11.74)$ & -0.134 & $(-0.92)$ \\
Food sales & $0.462^{* * *}$ & $(10.32)$ & $0.721^{* * *}$ & $(6.82)$ \\
Refreshment & $0.495^{* * *}$ & $(5.95)$ & 0.177 & $(1.75)$ \\
Finance \& commerce & $0.672^{* * *}$ & $(5.76)$ & $-1.06^{* *}$ & $(-3.00)$ \\
No occupation given & $0.279^{* *}$ & $(2.97)$ & -0.136 & $(-0.76)$ \\
\hline Constant & $8.285^{* * *}$ & $(38.27)$ & $7.539^{* * *}$ & $(8.73)$ \\
\hline Observations N & 36,877 & & 20,706 & \\
Wald Chi & & & $97.5^{* * *}$ & \\
\hline
\end{tabular}

Table A.1. Random effects panel estimates for Non-Farm employers and own account. Notes as Table 4 .

\begin{tabular}{lllll}
\hline & Employers & & Own account \\
\hline Age & $0.228^{* * *}$ & $(47.46)$ & $0.191^{* * *}$ & $(18.70)$ \\
Age $^{2}$ & $-0.001^{* * *}$ & $(-39.18)$ & $-0.001^{* * *}$ & $(-15.67)$ \\
\hline Density RSD & $-0.007^{* *}$ & $(-2.60)$ & $-0.050^{* * *}$ & $(-3.86)$ \\
Density RSD & $(000 \mathrm{~s})$ & $(2.19)$ & $0.179^{* * *}$ & $(3.70)$ \\
\hline Married & $0.028^{*}$ & $(6.21)$ & $0.146^{* *}$ & $(1.99)$ \\
Widowed & $0.207^{* * *}$ & $(5.37)$ & 0.162 & $(1.91)$ \\
\hline CFU member & $0.231^{* * *}$ & $(-9.20)$ & $-0.828^{* * *}$ & $(-3.36)$ \\
Older generation & $-1.026^{* * *}$ & $(-3.11)$ & 0.716 & $(1.05)$ \\
Siblings & $-1.330^{* *}$ & $(-5.10)$ & $-1.103^{* *}$ & $(-2.63)$ \\
Other family & $-1.166^{* * *}$ & $(-2.53)$ & 0 & $()$. \\
Servants & $-1.122^{*}$ & $()$. & 0 & $()$. \\
Working title & 0 & $(-1.13)$ & & $(-0.11)$ \\
Lodgers/boarders & -1.400 & $(-3.17)$ & -0.069 & $(-1.63)$ \\
Non-household & $-1.084^{* *}$ & $(-0.66)$ & & $(-9.48)$ \\
Unknown & -0.993 & $(-0.82)$ & -1.734 & $(-1.95)$ \\
\hline Female & -0.266 & $(-29.06)$ & $-0.730^{* * *}$ & $(-5.28)$ \\
\hline Urban transition & $-1.330^{* * *}$ & $(5.49)$ & -0.172 & $(-3.43)$ \\
Transition & $0.320^{* * *}$ & $(7.57)$ & $-0.404^{* * *}$ & $(4.08)$ \\
Rural & $0.377^{* * *}$ & $(7.54)$ & $-0.272^{* * *}$ & $(-6.27)$ \\
\hline Rail line distance & $0.374^{* * *}$ & $(-2.48)$ & $0.039^{* * * *}$ & $(0.28)$ \\
Rail station distance & $-0.011^{* *}$ & $(3.57)$ & $-0.056^{* * *}$ & $(-20.64)$ \\
\hline Acreage & $0.014^{* * *}$ & $(43.94)$ & 0.0001 & \\
\hline Constant & $0.002^{* * *}$ & $(-55.83)$ & $-6.138^{* * *}$ & 17,032 \\
\hline Observations N & $-7.598^{* * *}$ & & $1025.6^{* * * *}$ & \\
Wald Chi & 61,909 & & \\
\hline
\end{tabular}

Table A.2. Random effects panel estimates for Farm employers and own account. Notes as Table 4. 
These panel estimates use the random-effects estimation. They were checked against equivalent conditional fixed-effects logistic regression panel estimates. There is an inevitable reduction of $\mathrm{N}$ and the number of covariates that can be estimated because only within-panel variation is estimated in fixed-effect models, but where these results can be compared they confirm that the random effects panel is robust. A Hausman test comparing the coefficients in the FE and RE (where they are both estimated) confirms that the RE estimates quoted here are to be preferred. The coefficients are similar, with smaller standard errors. The Hausman test compared the models for employers for farmers and non-farmers, and own account for farmers and non-farmers. All four tests have a low and insignificant value, with respective probabilities under Chi-square test of $0.32,0.97,0.99$, and 0.99 . There is also only a small difference between the coefficient values of the RE and FE models.

\section{References}

Abramitzky, Ran, Roy Mill, and Santiago Pérez (2020) “Linking individuals across historical sources: A fully automated approach.” Historical Methods: A Journal of Quantitative and Interdisciplinary History (53): 94-111.

Anderson, Michael (1971) Family Structure in Nineteenth Century Lancashire, Cambridge: Cambridge University Press.

Anderson, Michael (1988) "Households, Families and Individuals: Some Preliminary Results from the National Sample from the 1851 Census of Great Britain.” Continuity and Change (3): 421-38.

Anderson, Michael (1999) "What Can the Mid-Victorian Censuses Tell Us about Variations in Married Women's Employment?" Local Population Studies (62): 9-30. 
Antonie, Luiza, Kris Inwood, Chris Minns, and Fraser Summerfield (2020) "Selection Bias

Encountered in the Systematic Linking of Historical Census Records.” Social Science History (44): 555-570 doi:10.1017/ssh.2020.15

Armstrong, W. A. (1972) “The Use of Information about Occupations,” in E. A. Wrigley (ed.)

Nineteenth-Century Society: Essays in the Use of Quantitative Methods for the Study of Social Data. Cambridge: Cambridge University Press: 191-210

Aronson, Robert L. (1991) Self Employment: A Labor Market Perspective. Ithaca, NY: ILR Press.

Aston, Jennifer (2016) Female Entrepreneurship in Nineteenth-Century England, Engagement in the Urban Economy. Basingstoke: Palgrave Macmillan.

Aston, Jennifer, and Catherine Bishop (eds.) (2020) Female Entrepreneurs in the Long Nineteenth Century: A Global Perspective. Basingstoke: Palgrave Macmillan.

Atack, Jeremy, Fred Bateman, and Mary E. Gregson (1992) "Matchmaker, Matchmaker, Make Me a Match.” Historical Methods: A Journal of Quantitative and Interdisciplinary History (25): 53-65.

Bailey, Martha, Connor Cole, Morgan Henderson, and Catherine Massey (2020) "How well do automated linking methods perform? Lessons from U.S. historical data." Journal of Economic Literature (584): 997-1044.

Bennett, Robert J., and Gill Newton (2015) "Employers and the 1881 population census of England and Wales." Local Population Studies (94): 29-49.

Bennett, Robert J., Harry Smith, Carry van Lieshout, and Gill Newton, Gill (2017) "Occupations and occupational aggregation of census data 1851-1911." Working Paper 5: Cambridge: University of Cambridge. https://doi.org/10.17863/CAM.9874

Bennett, Robert J., Harry Smith, Carry van Lieshout, Piero Montebruno, and Gill Newton (2019a) “The British Business Census of Entrepreneurs 1851-1911 (BBCE): User Guide.” Cambridge: University of Cambridge. https://doi.org/10.17863/CAM.47126 Additional resources at https://www.bbce.uk/ 
Bennett, Robert J., Harry Smith, Carry van Lieshout, Piero Montebruno, and Gill Newton (2019b)

The Age of Entrepreneurship: Business proprietors, self-employment and corporations since 1851. London: Routledge.

Bennett, Robert J., Harry Smith, Carry van Lieshout, Piero Montebruno, and Gill Newton (2020)

British Business Census of Entrepreneurs, 1851-1911. [data collection] UK Data Service. SN: 8600, http://doi.org/10.5255/UKDA-SN-8600-2

Bennett, Robert J., Harry Smith, Piero Montebruno, and Carry van Lieshout (2021) “Changes in Victorian entrepreneurship in England and Wales 1851-1911: Methodology and business population estimates.” Business History, forthcoming

Booth, Charles (1886) "Occupations of the People of the United Kingdom 1801-1881." Journal of the Royal Statistical Society (49): 314-435.

Cain, P.J., and G. Hopkins, (1993) British Imperialism, 1688-1914: Innovation and Expansion. Harlow: Longman.

Chandler, Alfred D. (1962) Strategy and Structure: Chapters in the History of the Industrial Enterprise. Cambridge Mass.: MIT Press.

Chandler, Alfred D. (1990) Scale and Scope: The Dynamics of Industrial Capitalism. London: Belknap Press.

Checkland, Sidney G. (1964) The Rise of Industrial Society in England 1815-1885. London: Longmans

Christen, Peter, Tim Churches, and Markus Hegland (2005) "Febrl - Freely extensible biomedical record linkage: Release 0.3.1.” http://users.cecs.anu.edu.au/ Peter.Christen/Febrl/febrl-0.3/febrldoc$\underline{0.3 / \text { manual.html }}$

Church, Roy (1993) “The Family Firm in Industrial Capitalism: International Perspectives on Hypotheses and History.” Business History (35): 17-43. 
Clapham, John H. (1932) An Economic History of Modern Britain, Vol. 2: Free trade and steel 18501886. Cambridge: Cambridge University Press.

Colli, Andrea (2003) The History of Family Business, 1850-2000. Cambridge: Cambridge University Press.

Crafts, Nicholas F.R.. and Abay Mulatu (2005) "What explains the location of industry in Britain, 1871-1931?" Journal of Economic Geography (5): 499-518.

Crossick, Geoffrey (1978) An Artisan Elite in Victorian Society: Kentish London 1840-1880.

London: Croom Helm.

Crossick, Geoffrey. and Heinz-Gerhard Haupt (1995) The Petite Bourgeoisie in Europe 1780-1914: Enterprise, Family and Independence. London: Routledge.

Davidoff, Leonore (1995) “The separation of home and work? Landladies and lodgers in nineteenth and twentieth century England," in L. Davidoff (ed.) Worlds Between: Historical Perspectives on Gender \& Class, London: Routledge: 151-80.

Davidoff, Leonore (2012) Thicker Than Water: Siblings and their Relationships 1780-1920. Oxford: Oxford University Press.

Davidoff, Leonore, and Catherine Hall (1997) Family Fortunes: Men and Women of the English Middle Class 1780-1850. (revised ed.) London: Routledge.

Dawson, Chris, Andrew Henley, and Paul Latreille (2014) "Individual motives for choosing selfemployment in the UK: Does region matter.” Regional Studies (48): 804-822.

Garrett, Eilidh, Alice Reid, Kevin Schürer, and Simon Szreter (2001) Changing Family Size in England and Wales: Place, Class and Demography, 1891-1911. Cambridge: Cambridge University Press.

Goeken, Ronald, Yu N. Lee, Tom Lynch, and Diana Magnuson (2017) Evaluating the Accuracy of Linked U. S. Census Data: A Household Linking Approach, Working Paper No. 2017-1. Minneapolis: University of Minnesota Population Center. 
Hannah, Leslie (2014) “Corporations in the US and Europe 1790-1860.” Business History (56): 86599.

Hatton, Timothy J., and Roy E. Bailey (2001) “Women's Work in Census and Survey, 1911-1931.” Economic History Review (54): 87-107.

Higgs, Edward (2005) Making Sense of the Census Revisited: Census Records for England and Wales 1801-1901. London: Institute of Historical Research, National Archives.

Higgs, Edward, C. Jones, Kevin Schürer, and Amanda Wilkinson (2015) Integrated Census Microdata (I-CeM) Guide. (second ed.) Colchester: University of Essex History Department. https://www.essex.ac.uk/research-projects/integrated-census-microdata\#the-i-cem-guide

Higgs, Edward, and Amanda Wilkinson (2016) "Women, Occupations and Work in the Victorian Censuses Revisited.” History Workshop Journal (81): 17-38.

Jeffreys, James B. (1954) Retail Trading in Britain, 1850-1950: A Study of Trends in Retailing with Special Reference to the Development of Co-operative, Multiple Shop and Department Store Methods of Trading. Cambridge: Cambridge University Press.

Kay, Alison, C. (2009) The Foundations of Female Entrepreneurship: Enterprise, Home and Household in London, c. 1800-1870. London: Routledge.

Knight, Frank H. (1921) Risk, Uncertainty and Profit, Boston, MA: Houghton Mifflin; reissued with additional Prefatory Essay, London School of Economics, 1933.

Lamoreaux, Naomi R. (1995) "Constructing Firms: Partnerships and Alternative Contractual Arrangements in Early-Nineteenth-Century American Business." Business and Economic History (24): 43-71.

Law, Chris M. (1967) “The growth of urban population in England and Wales, 1801-1911.” Transactions of the Institute of British Geographers (41): 125-43.

Lee, Clive H. (1981) "Regional Growth and Structural Change in Victorian Britain.” Economic History Review (34): 438-52. 
Long, Jason (2013) “The surprising social mobility of Victorian Britain.” European Review of Economic History (17): 1-23.

Long, Jason, and Joseph Ferrie (2013) "Intergenerational occupational mobility in Great Britain and the United States since 1850.” The American Economic Review (103): 1109-37.

Marlow, Susan, Collette Henry, and Sarah Carter (2009) "Exploring the impact of gender upon Women’s Business Ownership.” International Small Business Journal (29): 717-735.

Marshall, Alfred (1891) Principles of Economics, 2nd edn. quoted page nos. from 1961 variorum ed., London: Macmillan.

Marshall, Alfred (1919) Industry and Trade. London: Macmillan

Marshall, Alfred (1920) Principles of Economics, 8th edn. London: Macmillan.

Marshall, Alfred and Mary P. Marshall (1879) The Economics of Industry. London: Macmillan.

Massey, Catherine G. (2017) "Playing with Matches: An Assessment of Accuracy in Linked Historical Data." Historical Methods: A Journal of Quantitative and Interdisciplinary History (50): 115.

Miles, Andrew (1999) Social Mobility in Nineteenth- and Early Twentieth-Century England. Basingstoke: Macmillan.

Mitch, David (1993) “ 'Inequalities which every one may remove’: occupational recruitment, endogamy, and the homogeneity of social origins in Victorian England," in A. Miles and D. Vincent (eds.), Building European Society: Occupational Change and Social Mobility in Europe, 1840-1940. Manchester: Manchester University Press: 140-64.

Mitchell, B. R. (1964) “The coming of the railway and United Kingdom economic growth.” Journal of Economic History (24): 315-336. 
Montebruno, Piero, Robert J. Bennett, Carry van Lieshout, Harry Smith and Max Satchell (2019)

"Shifts in agrarian entrepreneurship in mid-Victorian England and Wales." Agricultural History Review (67): 71-108.

Montebruno, Piero, and Robert J. Bennett (2020) “Inter-census record-linked entrepreneurs and nonentrepreneurs 1851-91 using BBCE and I-CeM: database structure, assessment, downloads and User Guide.” WP 25, Cambridge: University of Cambridge. https://doi.org/10.17863/CAM.50180

“Entrepreneur sample 1851-91 download": https://doi.org/10.17863/CAM.50242

Morris, Roger J. (2005) Men, Women and Property in England, 1780-1870: A Social and Economic History of Family Strategies amongst the Leeds Middle Classes. Cambridge: Cambridge University Press.

Nenadic, Stana (1991) “Businessmen, the upper middle classes, and the 'dominance' of manufacturers in Nineteenth-Century Britain.” Economic History Review (44): 66-95.

Nenadic, Stana (1993) “The Small Family Firm in Victorian Britain.” Business History (35): 86-114.

Nenadic, Stana, Morris, Roger .J., Smyth, J. and Rainger, C. (1992) "Record linkage and the small family firm: Edinburgh 1861-1891.” Bulletin of the John Rylands Library (74): 169-88.

Newton, Gill, and Robert J. Bennett (2020) "Record-linkage of entrepreneurs in the England and Wales Censuses 1851-91 using BBCE and I-CeM.” Working Paper 24. https://doi.org/10.17863/CAM.50178

Novak, Mathew J., and Jason A. Gilliland (2011) “Trading Places: A Historical Geography of Retailing in London, Canada." Social Science History (35): 543-570.

Owens, Alastair (2002) "Inheritance and the Life-Cycle of Family Firms in the Early Industrial Revolution.” Business History (44): 21-46.

Parker, Simon C. (2012) The Economics of Entrepreneurship. Cambridge: Cambridge University Press. 
Payne, Peter L. (1988) British Entrepreneurship in the Nineteenth Century, 2nd. ed. London:

Macmillan.

Penrose, Edith T. (1959) The Theory of the Growth of the Firm. Oxford: Basil Blackwell

Pollard, Sidney (1965) The Genesis of Modern Management: A Study of the Industrial Revolution in Great Britain. Edward Arnold: London.

Porter Edward H., and William E. Winkler, (1997) “Approximate String Comparison and its Effect on an Advanced Record Linkage System. Research Report RR97/02.” Washington D.C.: US Bureau of the Census.

Radicic, Dragana, Robert J. Bennett, and Gill Newton (2017) "Portfolio entrepreneurship in farming: Empirical evidence from the 1881 census for England and Wales." Journal of Rural Studies (55): 289302. DOI: $10.1016 /$ j.jrurstud.2017.08.019

Robson, Brian (1973) Urban Growth: An Approach. London: Methuen

Rose, Mary B. (1994) “The family firm in British business, 1780-1914” in Maurice W. Kirby and Mary B. Rose eds. Business Enterprise in Modern Britain. London: Routledge: 61-87.

Samuel, Raphael (1975) Village Life and Labour. London: Routledge and Kegan Paul.

Schürer, Kevin, and Joe D. Day, (2019) "Migration to London and the development of the northsouth divide, 1851-1911.” Social History (44): 26-56.

Schürer, Kevin, Eilidh M., Garrett, Hanna Jaadla, and Alice M. Reid (2018) "Household and family structure in England and Wales (1851-1911): Continuities and change." Continuity and Change (33): $365-411$

Schürer, Kevin, and Edward Higgs (2014) Integrated Census Microdata (I-CeM), 1851-1911 [data collection], Colchester, Essex: UK Data Archive [distributor] SN: 7481, http://dx.doi.org/10.5255/UKDA-SN-7481-1 
Schürer, Kevin, Tatiana Penkova, and Y. Shi (2015) "Standardising and coding birthplace strings and occupational titles in the British censuses of 1851 to 1911." Historical Methods (48): 195-213.

Schwartz, Robert M. (2010) "Rail transport, Agrarian crisis, and the restructuring of agriculture: France and Great Britain confront globalization, 1860-1900.” Social Science History (34): 229-55 Simmons, Jack (1986) The Railway in Town and Country 1830-1914. Newton Abbot: David and Charles.

Smith, Harry, and Robert J. Bennett (2017) “Urban-Rural Classification using Census data, 18511911.” WP 6. Cambridge: University of Cambridge. https://doi.org/10.17863/CAM.15763

Smith, Harry, and Robert J. Bennett, Carry van Lieshout, and Piero Montebruno (2020) "Households and entrepreneurship in England and Wales, 1851-1911.” The History of the Family: https://doi.org/10.1080/1081602X.2020.1796750

van Der Zwan Peter, Ingrid Verheul, and Roy Thurik (2011) “The entrepreneurial ladder, gender and regional development.” Small Business Economics (39): 627-643.

van Lieshout, Carry, Robert J. Bennett, Harry Smith, and Gill Newton (2017) “Identifying businesses and entrepreneurs in the Censuses 1851-1881.” WP 3, Cambridge: University of Cambridge. https://doi.org/10.17863/CAM.9640

van Lieshout, Carry, Joe Day, Piero Montebruno, and Robert J. Bennett (2018) "Extraction of data on Entrepreneurs from the 1871 Census to supplement I-CeM.”, Working Paper 12, Cambridge: University of Cambridge. https://doi.org/10.17863/CAM.27488

van Lieshout, Carry, Harry Smith, Piero Montebruno, and Robert J. Bennett, (2019) "Female Entrepreneurship: Business, Marriage and Motherhood in England and Wales, 1851-1911.” Social History: (44) http://doi.org/10.1080/03071022.2019.1656929

van Lieshout, Carry, Robert J. Bennett, and Harry Smith (2020) “The British Business Census of Entrepreneurs and firm-size,1851-1881: New data for economic and business historians.” Historical 
Methods: A Journal of Quantitative and Interdisciplinary History.

https://www.tandfonline.com/doi/full/10.1080/01615440.2019.1707140

Wall, Richard (2002) "Elderly widows and widowers and their coresidents in late 19th- and early 20th-century England and Wales." History of the Family (7): 139-55

Wilson, John F., and Andrew Popp (eds.) (2003) Industrial clusters and regional business networks in England, 1750-1970. Aldershot: Ashgate.

Winstanley, Michael (1996) "Industrialization and the small farm: family and household economy in Nineteenth-Century Lancashire.” Past and Present (152): 157-95.

Winkler. William E. (2014) “Matching and Record Linkage.” WIREs Computational Statistics (6): $313-325$.

You, Xuesheng (2020a) “Women's labour force participation in nineteenth-century England and Wales: evidence from the 1881 census enumerators' books." Economic History Review (73): 106133.

You, Xuesheng (2020b) “Working with Husband? 'Occupation's Wife' and Married Women's Employment in the Censuses in England and Wales between 1851 and 1911. "Social Science History 44 (4): 585 - 613 DOI: https://doi.org/10.1017/ssh.2020.32

Zhichun Fu, H.M. Boot, Peter Christen, and Jun Zhou (2014) “Automatic record linkage of individuals and households in historical census data." International Journal of Humanities and Arts Computing (8): 204-225. 